\title{
The animal trypanosomiases and their chemotherapy: a review
}

\author{
FEDERICA GIORDANI ${ }^{1}$, LIAM J. MORRISON ${ }^{2}$, TIM G. ROWAN ${ }^{3}$, \\ HARRY P. DE KONING ${ }^{1}$ and MICHAEL P. BARRETT ${ }^{1}$ * \\ ${ }^{1}$ Wellcome Trust Centre for Molecular Parasitology, Institute of Infection, Immunity and Inflammation, College of \\ Medical, Veterinary and Life Sciences, University of Glasgow, Glasgow G12 8TA, UK \\ ${ }^{2}$ Roslin Institute, Royal (Dick) School of Veterinary Studies, University of Edinburgh, Easter Bush, Midlothian EH 25 \\ $9 R G, U K$ \\ ${ }^{3}$ Global Alliance for Livestock Veterinary Medicines (GALVmed), Doherty Building, Pentlands Science Park, Bush Loan, \\ Edinburgh EH26 OPZ, UK
}

(Received 30 March 2016; revised 6 Fune 2016; accepted 23 Fune 2016; first published online 10 October 2016)

SUMMARY

Pathogenic animal trypanosomes affecting livestock have represented a major constraint to agricultural development in Africa for centuries, and their negative economic impact is increasing in South America and Asia. Chemotherapy and chemoprophylaxis represent the main means of control. However, research into new trypanocides has remained inadequate for decades, leading to a situation where the few compounds available are losing efficacy due to the emergence of drug-resistant parasites. In this review, we provide a comprehensive overview of the current options available for the treatment and prophylaxis of the animal trypanosomiases, with a special focus on the problem of resistance. The key issues surrounding the main economically important animal trypanosome species and the diseases they cause are also presented. As new investment becomes available to develop improved tools to control the animal trypanosomiases, we stress that efforts should be directed towards a better understanding of the biology of the relevant parasite species and strains, to identify new drug targets and interrogate resistance mechanisms.

Key words: animal trypanosomiases, veterinary trypanocide, drug resistance, Trypanosoma congolense, Trypanosoma vivax, Trypanosoma brucei.

\section{INTRODUCTION}

The animal trypanosomiases (or trypanosomoses) include a variety of wasting diseases caused by unicellular protozoan parasites of the genus Trypanosoma (order Kinetoplastida). All relevant animal pathogenic trypanosomes ( $T$. vivax - subgenus Duttonella, T. congolense - subgenus Nannomonas and T. brucei spp. - subgenus Trypanozoon) (Fig. 1) belong to the Salivaria group (Haag et al. 1998), so-called because their transmission to the vertebrate host occurs principally via the infected saliva of blood-sucking insects. Most valuable domestic livestock (bovines, ovines, caprines, equids, camelids and suids) are susceptible to infection with one or more of these Trypanosoma species. This can lead to acute and/or chronic forms of wasting disease, causing high morbidity, mortality and infertility in the absence of treatment (Leach and Roberts, 1981; Connor, 1992). By affecting agricultural production and animal husbandry, the animal trypanosomiases have a high economic and

* Corresponding author: Wellcome Trust Centre for Molecular Parasitology, Institute of Infection, Immunity and Inflammation, College of Medical, Veterinary and Life Sciences, Sir Graeme Davies Building, University of Glasgow, 120 University Place, Glasgow G12 8TA, UK. E-mail: michael.barrett@glasgow.ac.uk social impact in vast areas of the tropics and subtropics where transmission occurs. Africa has historically suffered the greatest burden (Steverding, 2008), but the negative effects are also increasing in South America and South-East Asia, where unrestricted animal movements favour the spread of some trypanosome species.

Chemotherapy and chemoprophylaxis represent the mainstay of animal trypanosomiases control, ensuring animal health and production in enzootic countries. However, the available veterinary trypanocides (Table 1) are inadequate and outmoded. Only six compounds are currently licensed, and their narrow therapeutic indices restrict their use, especially when even low-level resistance arises. By far, the most usage is of two compounds, diminazene aceturate and isometamidium chloride, largely applied against animal trypanosomiases in Africa (Holmes et al. 2004), with suramin also being relatively widely used to treat $T$. $b$. evansi infections. Worryingly, an increasing number of reports of resistance to this handful of existing chemicals, particularly diminazene and isometamidium, indicate their future utility to be in jeopardy (Geerts et al. 2001; Delespaux and de Koning, 2007).

It has been estimated that as many as 35 million doses of trypanocides are used annually in subSaharan Africa alone (Holmes, 2013), which

Parasitology (2016), 143, 1862-1889. @ Cambridge University Press 2016. This is an Open Access article, distributed under the terms of the Creative Commons Attribution licence (http://creativecommons.org/licenses/by/4.0/), which permits unrestricted re-use, distribution, and reproduction in any medium, provided the original work is properly cited. 


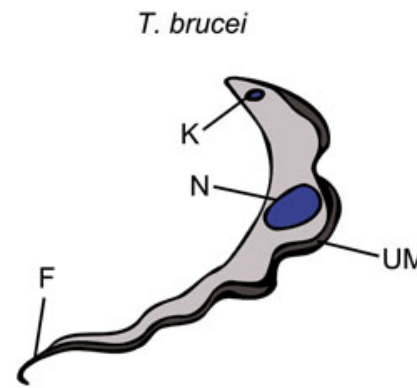

20-30 $\mu \mathrm{m}$ in length; pointed posterior end; nucleus $(\mathrm{N})$ is central; conspicuous undulating membrane (UM); free flagellum $(F)$ at anterior end; small kinetoplast (K);

polymorphic (long slender and stumpy forms).
T. congolense

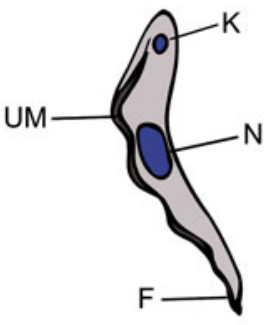

9-22 $\mu \mathrm{m}$ in length; rounded posterior end; nucleus $(\mathrm{N})$ is central; modest undulating membrane (UM); no free flagellum $(F)$;

subterminal, medium size kinetoplast $(\mathrm{K})$; essentially monomorphic.
T. vivax

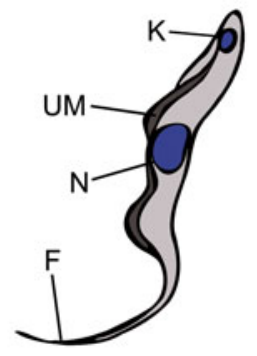

18-26 $\mu \mathrm{m}$ in length; rounded posterior end; nucleus $(N)$ is central; modest undulating membrane (UM); free flagellum $(F)$ at anterior end; terminal large kinetoplast $(\mathrm{K})$; essentially monomorphic.

Fig. 1. Morphological characteristics of the bloodstream form trypomastigote of the three most important livestock trypanosomes. T. brucei group trypanosomes (T. b. brucei, T. b. evansi, T. b. equiperdum) are morphologically indistinguishable (with the exception of the non-proliferative stumpy-form in $T . b$. brucei). The trypomastigote is the disease-relevant form and the target of therapy.

represents a figure suitable to treat only around onethird of the cattle at risk (Swallow, 2000). Inclusion of trypanocides sold informally in the African market may substantially increase the total number of doses sold annually, which may be as high as 70 million doses (Frans van Gool, personal communication, 2015). Despite this demand, the high costs of drug development and the low anticipated profit from the sale of chemotherapeutics in developing countries have disincentivized commercial pharmaceutical investments in this field (Connor, 1992). In recent years, a public-private partnership, GALVmed (Global Alliance for Livestock Veterinary Medicines), supported by funding from the Bill \& Melinda Gates Foundation and the UK Department for International Development, has emerged to fill the gap, and has committed to the development of new therapeutic and prophylactic trypanocidal drugs (http://www.galvmed.org/en/). However, even in the best case scenario, a novel licensed compound is unlikely to be available for several years yet; hence the rational, correct use of the trypanocides already available is of paramount importance.

THE ANIMAL TRYPANOSOMIASES:

DISTRIBUTION, TRANSMISSION, HOSTS,

PATHOLOGY AND ECONOMIC IMPACT

\section{Animal African trypanosomiasis (AAT, nagana)}

AAT [also called nagana, from the Zulu word 'N'gana' which means 'powerless/useless' (Steverding, 2008)], is caused by trypanosome species $T$. congolense, $T$. vivax and, to a lesser extent, T. brucei spp.
(Fig. 1). The disease is widespread in sub-Saharan Africa (Fig. 2), where it is cyclically transmitted by the tsetse fly (Glossina spp.), the same vector responsible for the transmission of human-infective trypanosomes ( $T$. brucei gambiense and $T$. b. rhodesiense, the aetiological agents of human African trypanosomiasis, HAT, or sleeping sickness) (Barrett et al. 2003). In animals, tsetse flies can also transmit trypanosomes mechanically when they begin a blood meal on an infected host and end it on another one, provided that the time between the two meals is short enough to ensure survival of parasites in the insect mouthparts, as shown in experimental infections in goats (Moloo et al. 2000). Unlike other trypanosomes, T. vivax does not multiply in the tsetse midgut, but remains confined to the insect proboscis, where it completes its short life cycle (Gardiner, 1989). This is the reason why this species can also be transmitted mechanically by other haematophagous flies, in particular horseflies (Tabanus spp.) and stable flies (Stomoxys spp.). Mechanical transmission has allowed T. vivax to spread far beyond the limits of the African tsetse belt: this parasite is now established in Mauritius and in 13 South American countries (Fig. 2), where it probably arrived in the 18 th or 19 th century via infected Zebu cattle exported from West Africa (Jones and Davila, 2001; Osorio et al. 2008), an origin corroborated by phylogenetic studies (Cortez et al. 2006). Although T. vivax remains enzootic in South America primarily due to mechanical transmission, other potential modes of transmission include perinatal and iatrogenic routes or via alternative, as yet unidentified vectors (Osorio et al. 2008). This lack of definitive knowledge greatly hampers the 
Table 1. Currently available veterinary trypanocides.

\begin{tabular}{|c|c|c|c|c|c|c|c|c|}
\hline Name & Trade names ${ }^{\mathrm{a}}$ & Structure & $\begin{array}{l}\text { Administration } \\
\text { route }\end{array}$ & Action & $\begin{array}{l}\text { Dosage } \\
\left(\mathrm{mg} \mathrm{Kg}^{-1}\right)^{\mathrm{b}}\end{array}$ & Indication/animal & $\begin{array}{l}\text { Adverse } \\
\text { effects/other } \\
\text { information }\end{array}$ & $\begin{array}{l}\text { Treatment of } \\
\text { relapses }\end{array}$ \\
\hline $\begin{array}{l}\text { Diminazene } \\
\text { aceturate }\end{array}$ & $\begin{array}{l}\text { Berenil, Veriben, } \\
\text { Pirocide, } \\
\text { Ganaseg, } \\
\text { Azidin, Trypan }\end{array}$ & & IM, SC & $\mathrm{T}$ & $\begin{array}{l}3 \cdot 5 \text { (up to } 8 \\
\text { for resistant } \\
\text { trypanosomes, } \\
5-10 \text { for } \\
\text { T. b. evansi) }\end{array}$ & $\begin{array}{l}\text { T. congolense, } \\
\text { T. vivax (less active } \\
\text { on T. b. brucei, } \\
\text { T.b. evansi)/Cattle, } \\
\text { sheep, goats, dogs }\end{array}$ & $\begin{array}{l}\text { Toxic to horses, } \\
\text { donkeys, dogs } \\
\text { and camels. Also } \\
\text { babesicidal }\end{array}$ & $\begin{array}{l}\text { Isometamidium } \\
\text { chloride }\end{array}$ \\
\hline $\begin{array}{l}\text { Homidium } \\
\text { bromide } \\
\text { Homidium } \\
\text { chloride }\end{array}$ & $\begin{array}{l}\text { Ethidium } \\
\text { Novidium }\end{array}$ & & $\begin{array}{l}\text { IM (deep, } \\
\text { cattle), IV } \\
\text { (sheep, goats, } \\
\text { pigs) }\end{array}$ & $\mathrm{T},(\mathrm{P})$ & 1 & $\begin{array}{l}\text { T. vivax, } \\
T . \text { congolense (less } \\
\text { active on } \\
T . \text { b. brucei)/Cattle, } \\
\text { sheep, goats, pigs }\end{array}$ & $\begin{array}{l}\text { IM toxic to } \\
\text { horses. } \\
\text { Potentially } \\
\text { carcinogenic }\end{array}$ & $\begin{array}{l}\text { Diminazene } \\
\text { aceturate, } \\
\text { Isometamidium } \\
\text { chloride }\end{array}$ \\
\hline $\begin{array}{l}\text { Isometamidium } \\
\text { chloride }\end{array}$ & $\begin{array}{l}\text { Trypamidium, } \\
\text { Samorin, } \\
\text { Veridium, } \\
\text { Securidium }\end{array}$ & & IM (deep) & $\mathrm{P}, \mathrm{T}$ & $\begin{array}{l}0 \cdot 25-1(\mathrm{~T}), 0 \cdot 5-1 \\
(\mathrm{P})\end{array}$ & $\begin{array}{l}\text { T. congolense, } \\
\text { T. vivax (less active } \\
\text { on T.b. brucei, } \\
\text { T.b. evansi)/Cattle, } \\
\text { sheep, goats, } \\
\text { horses, camels }\end{array}$ & $\begin{array}{l}\text { Toxic above } 2 \\
\mathrm{mg} \mathrm{Kg}^{-1} \text {. Avoid } \\
\text { subcutaneous } \\
\text { administration. } \\
\text { Highly irritant. } \\
\text { Possible local } \\
\text { reactions in } \\
\text { cattle. }\end{array}$ & $\begin{array}{l}\text { Diminazene } \\
\text { aceturate }\end{array}$ \\
\hline $\begin{array}{l}\text { Quinapyramine } \\
\text { sulphate:chlor- } \\
\text { ide }(3: 2 \mathrm{w} / \mathrm{w})\end{array}$ & $\begin{array}{l}\text { Antrycide, } \\
\text { Trypacide, } \\
\text { Noroquin, } \\
\text { Quintrycide, } \\
\text { Tribexin, } \\
\text { Triquin-S, } \\
\text { M7555, } \\
\text { Trypacide } \\
\text { prosalt }\end{array}$ & & $\mathrm{SC}$ & $\mathrm{T}$ & $\begin{array}{l}\text { 3-5 (T) (20-40 } \\
\text { for T. simiae) } \\
\text { (Camels, } \\
\text { horses, pigs, } \\
\text { dogs: dose } \\
\text { divided and } \\
\text { given at } 6 \mathrm{~h} \\
\text { intervals), } 7 \cdot 4 \\
\text { (P) }\end{array}$ & $\begin{array}{l}\text { T. b. evansi, } \\
\text { T. vivax, } \\
\text { T. congolense, } \\
\text { T. brucei, } \\
\text { T. b. equiperdum, } \\
\text { T. simiae/Camels, } \\
\text { horses, pigs, dogs, } \\
\text { cattle } \\
\text { (discouraged) }\end{array}$ & $\begin{array}{l}\text { Toxic at high } \\
\text { doses. Fast } \\
\text { resistance } \\
\text { acquisition }\end{array}$ & $\begin{array}{l}\text { Isometamidium } \\
\text { chloride, } \\
\text { Suramin } \\
\text { sodium }\end{array}$ \\
\hline Suramin sodium & $\begin{array}{l}\text { Naganol, Bayer } \\
\text { 205, Germanin }\end{array}$ & & IV & $\mathrm{T}(\mathrm{P})$ & $\begin{array}{l}10 \text { (horses: } 3 \\
\text { doses/1 week) }\end{array}$ & $\begin{array}{l}\text { T. b. evansi, } \\
\text { T. b. brucei, } \\
\text { T. b. equiperdum/ } \\
\text { Camels, horses }\end{array}$ & $\begin{array}{l}\text { IM can cause } \\
\text { severe necrosis } \\
\text { at injection site. } \\
\text { May be toxic to } \\
\text { horses }\end{array}$ & $\begin{array}{l}\text { Quinapyramine } \\
\text { sulphate }\end{array}$ \\
\hline
\end{tabular}




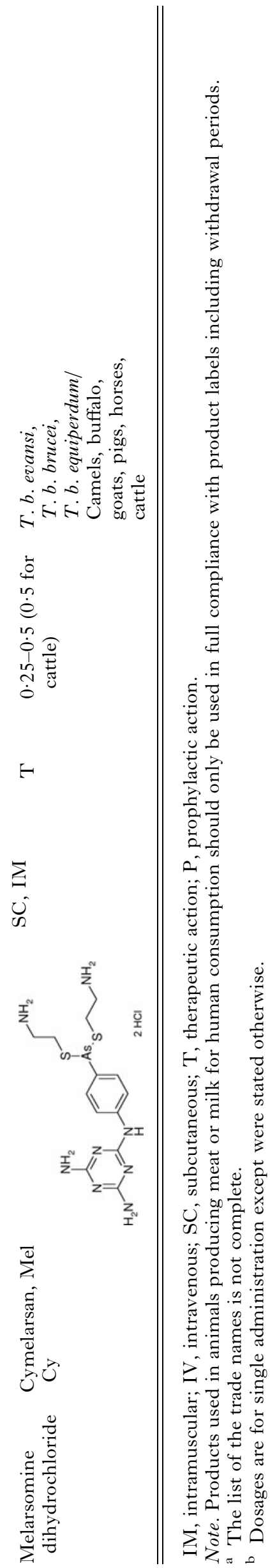

implementation of surveillance and control strategies (Jones and Davila, 2001). Non-tsetse transmitted $T$. vivax infection in cattle is also recognized in parts of Africa, for example in regions of Ethiopia, Chad and Sudan (Ahmed et al. 2016). Mechanical transmission of $T$. congolense has been shown under experimental conditions (Desquesnes and Dia, 2003) and can therefore not be excluded from contributing to its spread in Africa (Desquesnes et al. 2009).

The host range is wide (Uilenberg, 1998). Trypanosoma congolense is considered the most pathogenic trypanosome in cattle (followed by $T$. vivax), but it also causes infections in horses, sheep, goats, pigs and dogs. Apart from bovines, $T$. vivax can affect sheep, goats, horses and camels (Osorio et al. 2008). Trypanosoma b. brucei is found in various domestic ungulates but it is particularly virulent in dogs, camels and horses, the latter often succumbing to infection within a few months in the absence of treatment. In areas where more than one trypanosome species is present, mixed infections in domestic animals are often encountered (Kihurani et al. 1994; Auty et al. 2008; Biryomumaisho et al. 2013; Takeet et al. 2013; Moti et al. 2015) and modern molecular techniques (Desquesnes and Davila, 2002) facilitate speciation. Many wild animal species in Africa also host one or more trypanosome species and can serve as reservoirs for both human and domestic animal infective trypanosomes (Mulla and Rickman, 1988; Auty et al. 2012). Similarly, wild South American fauna can harbour T. vivax and act as reservoir of infection (Osorio et al. 2008).

Belonging to the same Nannomonas subgenus as $T$. congolense, $T$. simiae is the only trypanosome species to be extremely pathogenic to pigs, which represent the main host, although other domestic species can harbour the parasite (Joshua and Kayit, 1984; Salim et al. 2014). In pigs, T. simiae causes a hyperacute, often fatal infection, with death often occurring within $48 \mathrm{~h}$ of the appearance of symptoms (Leach and Roberts, 1981). For this reason, chemoprophylaxis is preferred to curative treatment.

The pathogenicity of trypanosomal infections varies considerably depending on several factors, including parasite-related aspects (species and virulence), host (species, breed, age, immunological status, nutritional status, presence of co-infection and physical condition), vector (species, density, infection rate and host preference), epidemiological situation (endemic or epidemic) and the environment (e.g. the availability of food and water and the season) (Leach and Roberts, 1981; Van den Bossche and Delespaux, 2011). Anaemia is the most prominent pathological feature of AAT (Taylor and Authié, 2004) and, in conjunction with other systemic lesions, can contribute to death through eventual congestive heart failure. Other symptoms include pyrexia, lymph node and spleen 


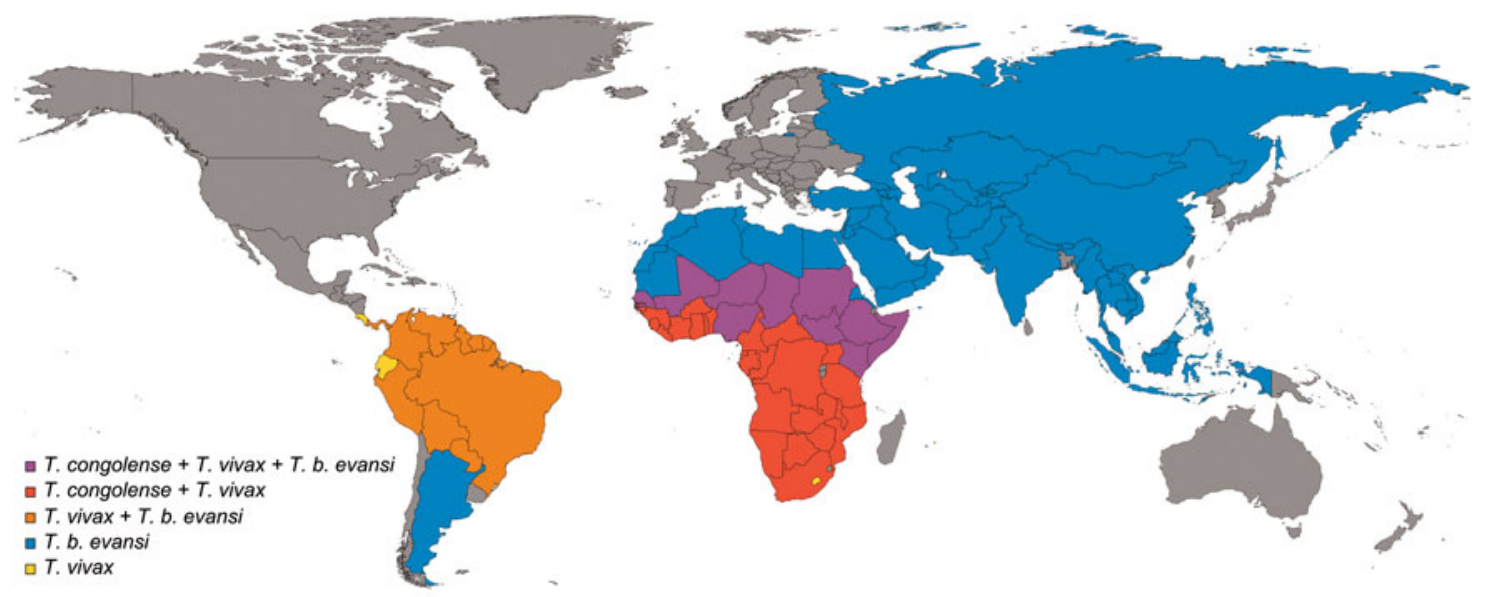

Fig. 2. Countries where the most important livestock trypanosomes are present. Modified from (Auty et al. 2015), based on PubMed search and including countries where data were not available and parasite presence is inferred. To note that the real geographical distribution in some countries is limited (as, for example, for T. congolense in South Africa, Namibia and Botswana and for T. b. evansi in Russia). Cases of eradicated outbreaks of T. b. evansi in Europe (i.e. in France) are not indicated.

enlargement, ataxia, lethargy, weight loss, oedema, immunosuppression, abortion and decrease in milk production. The immunosuppression caused by trypanosomes can affect animal health by interfering with vaccination against other diseases (Singla et al. 2010), or by increasing susceptibility of the host to other infections. Inflammatory, degenerative lesions are also observed, and can damage various organs such as heart, central nervous system (CNS), eyes, testes, ovary and pituitary gland. Death may occur within weeks from onset of the acute disease. Otherwise the animal enters a chronic phase (spontaneous recovery is rare but not unknown), characterized by intermittent or subpatent parasitaemia, general malaise and infertility, and may last months or years prior to death (Taylor and Authié, 2004).

While mortality due to the disease is clearly important, the impact upon overall cultivation and crop production due to reduced draught power is the most significant contributor to the economic impact of AAT (Swallow, 2000). This is considered the livestock disease with the highest impact on agricultural production and animal husbandry in Africa, causing annual losses which run to billions of US\$ (Shaw et al. 2014). Across the tsetse belt as many as 55 million cattle are at risk of infection (Cecchi and Mattioli, 2009), plus 30 million sheep and 40 million goats. Of these cattle, 3 million die every year from AAT. The disease has devastating effects on the livelihoods of local farmers, for whom cattle represent not only a source of food (meat and milk), manure, and draught power, but have also fundamental social roles as 'living banks' and are used for social obligations (e.g. dowry and ritual use) (Swallow, 2000; Grace et al. 2009; Mungube et al. 2012).
Infection with $T$. vivax is considered an emerging disease in South America where it has a significant impact on cattle farming, but where it also affects horses and other ruminants (Batista et al. 2007, 2009, 2012; Da Silva et al. 2011). In a region including the Brazilian Pantanal and the Bolivian lowlands, where cattle ranching is the single most important economic activity (11 million head of cattle are reared in the region), the losses caused to the industry by a single outbreak of $T$. vivax in 1995 were calculated at more than US\$ 160 million (Seidl et al. 1999). The gross financial burden of $T$. vivax in South America, however, is not known with any degree of certainty.

\section{Surra}

Surra (from the Hindi word for 'rotten') is the most widely used of a plethora of names given to $T$. b. evansi infection in animals (Desquesnes et al. 2013b). As seen for T. vivax, T. b. evansi (a $T$. brucei subspecies) has also evolved a mechanical mechanism of transmission that has allowed this species to spread beyond Africa by export of infected animals (Lun et al. 2010). Trypanosoma b. evansi is today the pathogenic animal trypanosome with the broadest geographical distribution (Fig. 2), which stretches from North-East Africa to much of Asia in the east (Luckins, 1988; Payne et al. 1991; Lun et al. 1993) and to Latin America in the west (Desquesnes et al. 2013b), and it is spreading steadily. In Europe, recent imported cases of surra have been documented and vigilance remains necessary after outbreaks in the Canary Islands, mainland Spain, France and Germany (Desquesnes et al. 2008; Gutierrez et al. 2010; Tamarit et al. 2011; Defontis et al. 2012). 
Several probable or suggested methods of surra transmission exist: by biting insects including horseflies and stable flies (the major credited route), by vampire bats, by iatrogenic (e.g. as a result of a vaccination intervention), sexual, horizontal or vertical transmission, or by per-oral contamination in the case of carnivores eating infected meat (Desquesnes et al. 2013a).

Trypanosoma b. evansi can parasitize a wide range of wild and domestic animal hosts, but the infection is particularly pathogenic in horses, camels and Asian water buffaloes (Desquesnes et al. 2013b). There is increasing evidence that common rodents are an important reservoir host for $T$. b. evansi and other trypanosomes (Jittapalapong et al. 2008; Maia da Silva et al. 2010; Kocher et al. 2015; Pumhom et al. 2015), such as T. lewisi, a parasite of rats also found in atypical human infections (Howie et al. 2006; Sarataphan et al. 2007). These findings revive the important question of rodents as reservoirs of other $T$. brucei species. Rare cases of human infection with $T$. b. evansi (Joshi et al. 2005; Haridy et al. 2011; Van Vinh et al. 2016), where individuals were infected through trypanosome-carrying animal blood, have been reported and, in at least one case, infection was associated with a null mutation in the trypanosome lytic factor blood component Apolipoprotein L1 (APOL1), which normally protects humans from animal trypanosome infections (Vanhollebeke et al. 2006; Truc et al. 2013). In a more recent case, no mutations in APOL1 were found to explain the unusual infection (Van Vinh et al. 2016).

Symptoms of surra overlap those previously described for AAT and their intensity can vary greatly between and within host species and depend on the geographical area and epidemiological situation (Desquesnes et al. 2013b).

In the Philippines, outbreaks of surra cause high morbidity and mortality in water buffaloes and other large ruminants, greatly affecting the livelihood of local small-scale farmers (Dargantes et al. 2009; Desquesnes et al. 2013a). In the Brazilian Pantanal T. b. evansi affects over 6000 horses per year (of the 50000 present), with serious consequences to the local economy, horses being essential for herding livestock. The total impact of T.b.evansi infection in horses in this region was estimated at US $\$ 2.4$ million per year (Seidl et al. 1998). Surra is also one of the most frequent diseases affecting camels in North Africa, causing severe economic damage.

\section{Dourine}

Dourine is a disease caused by the subspecies T. brucei equiperdum, the only Salivarian trypanosome whose transmission cycle avoids invertebrate vectors completely. Instead, this parasite is transmitted among horses and other equids during mating (Claes et al.
2005). Of note, vertical or perinatal transmission of trypanosomes other than T. b. equiperdum in the reproductive tissues has been reported (Griffin, 1983; Melendez et al. 1993; Lindner and Priotto, 2010; Biteau et al. 2016), although the role and relative importance of this mode of transmission in the field is not clear.

Trypanosoma b. equiperdum is an important veterinary trypanosome endemic in Africa and Asia, and is also found in the Middle-East, South-East Europe and South America. Strict control policies have eradicated $T$. b. equiperdum from Western Europe in the past century (Claes et al. 2005), but the risk of reintroduction remains, as shown by a recent outbreak in Italy (Pascucci et al. 2013).

The infection presents with typical oedema of the genital organs as well as weakness, emaciation, urethral discharge, characteristic plaques in the skin and neurological symptoms such as lack of coordination of the hind legs (Hagos et al. 2010). Dourine in horses is generally fatal without treatment but it is usually subclinical in donkeys and mules (Brun et al. 1998).

Considering the transmission mechanism and the absence of a reservoir in other species, the control strategies for the disease follow a different approach as compared with other insect-borne forms of trypanosomiasis (Claes et al. 2005). The World Health Organization for Animal Health (OIE) recommends breeding and movement restrictions, compulsory notification and slaughter of infected animals to block new infection outbreaks or achieve eradication. Additionally, pharmacological therapy is not advised as this may result in clinical improvement but not in complete cure, leaving the animal as a potential carrier of the parasite. However, the feasibility or effectiveness of this strict policy in developing countries, where horses have a significant role in transport and agriculture, is questionable. Here, chemotherapy may help to sustain animal health and productivity. Although no official cure for dourine is available, studies have indicated the efficacy of melarsomine in the treatment of acute and chronic $T$. b. equiperdum infection in horses (Hagos et al. 2010).

ANIMAL TRYPANOSOME SPECIES: VIRULENCE, TISSUE DISTIBUTION, BIOLOGY AND LABORATORY TOOLS

Trypanosoma congolense and T. simiae

Trypanosoma congolense is the smallest of the pathogenic trypanosomes (see Fig. 1 for its morphology). The species is divided into three main subgroups (i.e. Savannah, Forest and Kilifi) based on molecular markers (Hide and Tait, 2004; Auty et al. 2015), the Savannah subgroup being the most virulent (Bengaly et al. $2002 a, b)$ and the most clinically important in cattle. However, even within the same Savannah 
subgroup substantial differences in virulence exist, with some strains causing only mild infections (Masumu et al. 2006), highlighting the complexity and subtlety of the balance between the level of parasite persistence and the host immune system.

In the vertebrate host, $T$. congolense parasites remain confined to the vascular system, where they bind to circulating erythrocytes (Banks, 1979) and to endothelial cells (Hemphill et al. 1994) through their flagellum, causing damage at the adhesion site (Banks, 1980). Attachment of the bloodstream form is also observed in in vitro culture, where parasites adhere to the bottom of the flask, a phenotype unique to $T$. congolense among trypanosome species (Coustou et al. 2010).

Today, long-term culture of the pathogenic bloodstream form is possible only for a limited number of strains (e.g. IL3000 and STIB910) (Coustou et al. 2010). Genetic tools have been developed for this species, including a gene overexpression system (Coustou et al. 2010) and RNA interference (although, in this case, only for the procyclic insect form) (Inoue et al. 2002; Coustou et al. 2010). A draft genome sequence of strain IL 3000 has also been published (Jackson et al. 2012) and offers the potential to accelerate discovery of biomarkers for diagnosis and targets for new drugs. However, despite the veterinary importance of $T$. congolense, the data available to understand its biology and pathogenicity and, therefore, to improve treatment, are scanty. It appears that this parasite has a carbohydrate metabolism that differs significantly from that of the far more widely studied $T$. bruce $i$ (Agosin and von Brand, 1954), with indications of a more pronounced mitochondrial activity in its bloodstream form. These dissimilarities may have relevance in the very different responses of these species to trypanocides (Leach and Roberts, 1981) and in the identification of potential drug targets. Of note, $T$. congolense lacks an orthologue of the $T$. brucei TbAT1 gene that encodes the P2 nucleoside transporter (see subsection Diminazene aceturate below), which is central to the uptake of the trypanocidal drug diminazene (Munday et al. 2013). Trypanosoma congolense has a correspondingly reduced sensitivity to diminazene, which is not accumulated to the same degree in these parasites.

Similarly, the closely related $T$. simiae does not easily infect common laboratory rodents and, therefore, little data on this organism is available. However, a method for the axenic in vitro culture of the bloodstream form of this parasite has been published (Zweygarth et al. 1992), offering the means to accelerate our ability to dissect the parasite's biology.

\section{Trypanosoma vivax}

Among African trypanosomes, T. vivax (Fig. 1) is the most phylogenetically distinct species (Fig. 3).
Specific isolates present with different pathogenicity in cattle, in some cases causing chronic, sub-clinical infections and in others acute, haemorrhagic infections (Wellde et al. 1983; Magona et al. 2008).

Although T.vivax (as T. congolense) has been considered typically to remain confined to the vascular system of the host, some strains may, especially in late infections, also reach extravascular locations (e.g. lymph nodes, eyes and cerebrospinal fluid) where they may directly damage tissues and where they are less accessible to drug treatment (Whitelaw et al. 1988; Osorio et al. 2008; D'Archivio et al. 2013).

Trypanosoma vivax is generally difficult to cultivate in the laboratory and this has restricted biological studies into this parasite. Short-term, axenic culture systems for the bloodstream form have been reported (Brun and Moloo, 1982; Zweygarth et al. 1991; D'Archivio et al. 2011) but they have been difficult to reproduce in other laboratories and have not entered routine use. Most studies on this trypanosome species are, therefore, conducted in in vivo laboratory models; however, very few $T$. vivax strains have been isolated that readily infect rodents and most published in vivo work on this species comprises the very few mouse-infective strains, the main one being Y486 and its derivatives (Gibson, 2012). A simplified system for in vitro cultivation of the insect form of $T$. vivax was recently described and genetic manipulation methodology implemented (D'Archivio et al. 2011). As with $T$. congolense, studies into the biochemical physiology of $T$. vivax have lagged behind those in $T$. brucei but significant differences with the metabolism of bloodstream form $T$. brucei were clear from early studies (Desowitz, 1956), which probably explains incongruence in potency of different chemical classes against these species.

\section{Trypanosoma brucei $s p p$.}

Trypanosoma brucei spp. (Fig. 1) include both animal (T. b. brucei, T. b. evansi, T. b. equiperdum) and human (T.b. rhodesiense, T. b. gambiense) infective subspecies. Unlike $T$. vivax (most strains at least) or $T$. congolense, $T$. brucei group trypanosomes are found in both the vascular system and in other tissues, and can parasitize the brain in experimental infections (Moulton, 1986; Grab and Kennedy, 2008; Coles et al. 2015); descriptions of this clinical condition in field settings are limited, other than for equids, which are particularly susceptible to T. brucei (Tuntasuvan et al. 1997; Ranjithkumar et al. 2014). As the most widely used drugs to treat animal trypanosomes (diminazene and isometamidium) do not cross the blood-brain barrier, the presence of parasites in sites other than the bloodstream represents a potentially important issue for treatment of $T$. brucei. Parasites from inaccessible 


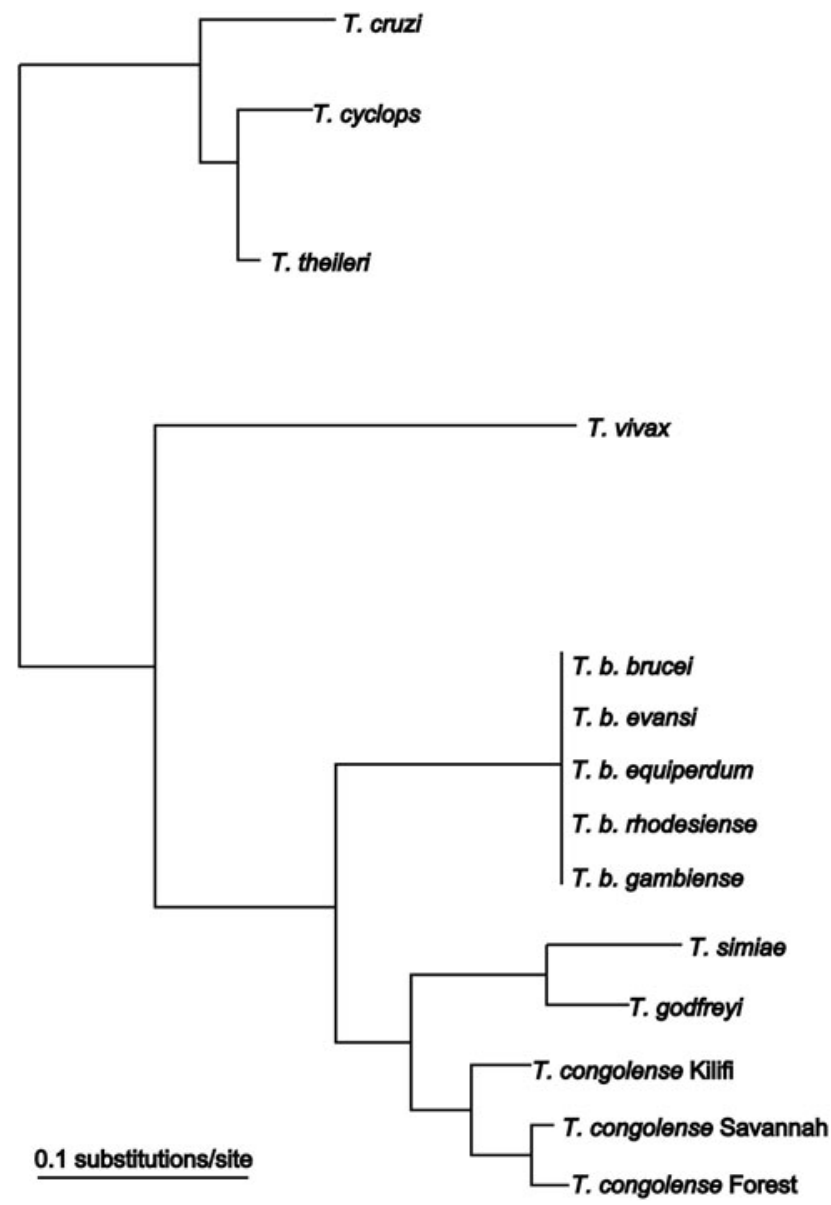

Fig. 3. Phylogenetic tree based on SSU rRNA sequences from trypanosome species. Modified from (Cortez et al. 2006).

body sites including the CNS may eventually re-establish infection in the bloodstream and cause relapse following treatment with these drugs (Myburgh et al. 2013). Trypanosoma b. equiperdum is quite unique, it being mainly a tissue parasite, found in the capillaries of the urogenital tract and rarely in peripheral blood (Brun et al. 1998). This makes diagnosis, parasite isolation and treatment particularly difficult.

Trypanosoma $b$. brucei is the most extensively studied trypanosome. Some lineages (e.g. Lister 427 ) are well adapted to laboratory in vitro culture and have been used as model organism to study many eukaryotic cell processes. The genome of this species was published in 2005 (Berriman et al. 2005) and its metabolism has been widely studied (Shameer et al. 2015). It has long been known that, in its bloodstream form, T. brucei species depend entirely on glycolysis for energy production, while Krebs cycle and oxidative phosphorylation are active only in the insect stages. New, comprehensive metabolomics approaches (Creek et al. 2015) are modifying this paradigm and, in conjunction with transcriptomic approaches, a clearer understanding of trypanosome metabolism is emerging.

Trypanosoma $b$. evansi and T. b. equiperdum can be considered petite mutants of $T$. brucei, so named after petite mutants of yeast that have lost mitochondrial respiratory function. These parasites have lost part (dyskinetoplastic parasites) or all (akinetoplastic parasites) of their kinetoplast DNA (kDNA), which constitutes the mitochondrial genome and comprises a network of circular concatenated mini- and maxi-circles (Schnaufer et al. 2002; Lai et al. 2008). Although long considered as two separate species, it has been proposed that $T$. b. evansi and T. b. equiperdum be reclassified as subspecies of $T$. brucei, based on phylogenetic analysis of sequenced genomes (Carnes et al. 2015), and we have adopted this convention here. As the kinetoplast genome encodes for an essential subunit $\left(\mathrm{F}_{0}-\mathrm{A} 6\right)$ of the mitochondrial $\mathrm{F}_{1} \mathrm{~F}_{0}$ ATP synthase, T. b. evansi and T. b. equiperdum cannot complete their life cycle in the fly and are locked in the trypomastigote stage, which relies on glycolysis for ATP production. A compensating mutation in the nuclear genome-encoded $\gamma$-subunit of the ATP synthase allows these parasites to maintain their mitochondrial membrane potential irrespective of the $\mathrm{F}_{0}$-A6 subunit and, therefore, to survive in the absence of the kinetoplast genome (Dean et al. 2013). It is for this reason that these parasites lost their dependency on the tsetse fly for transmission. 
CONTROL STRATEGIES AND

TRYPANOTOLERANCE

All of the important livestock trypanosomes described above are extracellular parasites in mammals and evade the host immune defences by continuously changing their surface coat (Horn, 2014), one of the immune-evading mechanisms that essentially preclude the development of conventional vaccines (La Greca and Magez, 2011; Cnops et al. 2015). Hence, control of animal trypanosomiases relies primarily on the use of insecticides or traps to control the vector (especially in the case of tsetse-transmitted trypanosomiases), and on the use of trypanocides to control the parasite (Holmes, 2013). (The control strategy for dourine follows a completely different approach and has been described separately; see subsection Dourine above). Since vector control can be expensive when used on a large scale and is not always sustainable or effective, administration of trypanocidal drugs represents the main intervention tool in most poor rural endemic areas, ensuring maximum effects at relatively little cost (Grace et al. 2009; Van den Bossche and Delespaux, 2011). The cost-effectiveness of this practice was shown both in Africa (at least under certain circumstances) (Shaw et al. 2015) and elsewhere (Seidl et al. 1998, 1999; Dobson et al. 2009). Control of parasites with chemotherapeutic and chemoprophylactic agents has the double effect of limiting the losses caused by the infection and of eliminating the transmissible trypanosome reservoir (Welburn et al. 2015). Effective treatment of the acute phase of infection usually leads to prompt recovery of the animal; the use of trypanocides in the chronic phase, however, usually clears parasitaemia, but clinical recovery in these instances may require a significantly longer time, depending on the severity of symptoms such as weight loss and organ damage.

Some indigenous African livestock breeds (e.g. N'Dama, Muturu and Dahomey) are more resistant to trypanosome infection than imported breeds (classically temperate 'European' taurine breeds but also including Asian-derived Bos indicus breeds, relatively new to trypanosome endemic areas, such as Boran). This phenomenon is called 'trypanotolerance' and is defined as the 'capacity to survive and remain productive after trypanosome infection' (Murray et al. 1982). A major factor enabling these animals to cope with trypanosome infections is a better capacity to limit both anaemia and parasitaemia (Naessens, 2006). The use of trypanotolerant breeds has helped livestock productivity in various endemic regions in Africa and elsewhere, and it is often advocated as an important control strategy. Wild animals, which have co-evolved with trypanosomes, are also usually trypanotolerant and rarely suffer from clinical disease when infected.
TREATMENT STRATEGIES AND CHALLENGES

Treatment and prophylaxis of pathogenic trypanosome infections in animals relies on only six compounds (Table 1), most dating back to the first half of the 20th century (Leach and Roberts, 1981). Moreover, several factors limit their use. The current drugs all have small therapeutic indices and can also cause local irritancy at the injection site. Most importantly, extensive utilization in the past has led to the appearance of resistant parasites in the field, and the fact that many of these trypanocides are chemically related has exacerbated the situation with cross-resistance onset (Peregrine, 1994). A number of currently used compounds appear to target the kinetoplast, causing its loss (Shapiro and Englund, 1990; Chitambo and Arakawa, 1992b), but the actual mode of action of these trypanocides and the biochemical mechanisms underpinning resistance are largely unclear. As noted above, differences in biochemical physiology and host organ distribution discriminate each of the veterinary trypanosomes and, therefore, the different trypanocides have divergent ability to kill based on specific potency against each species and pharmacokinetic parameters affecting distribution.

Most trypanocides have therapeutic rather than prophylactic activity, but the phenanthridine isometamidium is mostly used for its prophylactic effects (Stevenson et al. 1995). Unfortunately, these drugs are less active against $T$. b. evansi (Toro et al. 1983) and are less used outside of sub-Saharan Africa (Reid, 2002). The decision as to whether to use therapeutic or prophylactic drugs depends on several factors, including the risk of infection, drug availability and distribution logistics ( $\mathrm{Gu}$ et al. 1999). Ideally, in areas of low prevalence, only those animals that present with clinical disease attributable to trypanosomes and/or have confirmed infection should be treated with therapeutic drugs; instead, in areas of high challenge, prophylactic drugs applied to the whole herd are more costeffective, providing much greater reduction of mortality and morbidity and avoiding the adverse effects of infection on productivity (Gu et al. 1999). Singledose therapeutic and prophylactic products for cattle are preferred, as multiple-dose administration regimens are often not practical in developing countries, where animal handling facilities are typically very limited.

As new compounds are not likely to become available in the near future (i.e. the most optimistic outlook is at least $3-5$ years before a new compound could realistically be expected to be registered through current initiatives), prudent use of those already on the market is paramount. However, in field settings drug usage is often difficult to monitor and regulate. In hyperendemic African countries, trypanocides are usually administered 
directly by farmers, who can easily obtain them at local markets for a relatively affordable price (for less than US\$ 1 per treatment). Unfortunately, most livestock keepers in the affected regions have limited access to tools which (a) enable accurate diagnosis, and frequently farmers are reliant solely on clinical signs, which are often not pathognomonic; and (b) provide information or training regarding optimal drug usage and dosage, and this combination of factors can lead to drug misuse (Van den Bossche et al. 2000; Grace et al. 2009). Moreover, in an unregulated market, poor quality or counterfeit trypanocides are widespread in some areas, especially in Africa, where documented product specifications are scarce (Sutcliffe et al. 2014; Tchamdja et al. 2016). To improve veterinary drug standards and tackle the issue of counterfeit drugs two laboratories for trypanocide quality control checks were recently set up in Africa (one in Dakar and one in Dar Es Salaam) thanks to a GALVmed-FAO (Food and Agriculture Organization of the United Nations) initiative with other collaborating partners (Sutcliffe et al. 2014).

Besides correct dosage administration, various other options to extend the life of current trypanocides exist. Different approaches (such as delivery systems including complexing to polymeric substances promoting slow release or alternative formulations) have been considered in order to improve therapeutic efficacy (Peregrine, 1994; Geerts et al. 1999; Kroubi et al. 2011; Unciti-Broceta et al. 2015). These could allow the use of lower quantities of trypanocide in a more effective way and, consequently, pose a decreased risk of toxicity and possibly decreased resistance development.

Unlike the situation with HAT, where the nifurtimox-eflornithine combination therapy (NECT) is now the preferred first line treatment for secondstage disease (Priotto et al. 2009; Alirol et al. 2013), no drug combinations are currently used for the animal trypanosomiases. Instead, alternating use of compounds, particularly diminazene and isometamidium (called a 'sanative pair'), with low risk of cross-resistance, is recommended where possible. In particular, in the case of relapse the animal should be treated with a different drug class from the one previously administered, in order not to reinforce drug resistance selection (Leach and Roberts, 1981). Due to the chemical relatedness of several veterinary trypanocides, however, this approach is not always practicable. Thus, in order to maintain the efficacy of the currently used compounds, it is important that chemotherapeutic and chemoprophylactic dosage regimens are rationalized on the basis of the drug-susceptibility phenotype of trypanosome populations in a given locality. However, such rationalization is not possible, because the systems that are currently available to characterize the drug resistance phenotype of trypanosome populations are not field applicable (Peregrine, 1994). Limited numbers of field isolates can be characterized and all of the systems take many months to provide definitive data (see section Tests for resistance detection below). There is therefore a requirement for new assays that will rapidly quantify the drug resistance phenotype of large numbers of trypanosome isolates.

VETERINARY TRYPANOCIDES: DOSAGE, PHARMACOKINETICS, MODE OF ACTION AND RESISTANCE

\section{Diminazene aceturate}

Diminazene aceturate (Table 1) was introduced for the treatment of babesiosis and African trypanosomiasis in livestock in 1955. It belongs to the diamidine class of compounds, a member of which (pentamidine) has also been used for HAT since the 1930s (Steverding, 2010). Ironically, it was pursuing a structure-activity iterative synthesis from a compound belonging to a different class, Surfen C [at the time of its introduction in the $1930 \mathrm{~s}$, the best available agent against $T$. congolense infections (Bennett, 1936)], that led to diminazene development (Hawking, 1963). Although it was anti-T. congolense activity in experimental rodents that initially drove development, today's in vitro systems, where anti-parasite potency can be tested without confounding issues related to pharmacokinetic behaviour in hosts, show that diminazene is substantially less potent against $T$. congolense than it is against $T$. brucei group trypanosomes. This feature is attributable to the fact that its uptake into the latter parasites via the P2/TbAT1 transporter (see later) allows concentrative and rapid uptake (De Koning et al. 2004). In T. congolense, which lacks an orthologue of TbAT1 (Munday et al. 2013), uptake is less robust, explaining its lower activity.

Diminazene is today the most commonly used trypanocide in cattle, sheep and goats, due to its activity against both $T$. congolense and $T$. vivax and its relatively low toxic side effects. The compound also effectively cures surra and is, for example, the mainstay of treatment of T. b. evansi in the Philippines (Reid, 2002). The recommended therapeutic dose is $3.5 \mathrm{mg} \mathrm{kg}^{-1}$ body weight for AAT due to $T$. congolense and $T$. vivax $\left(7 \mathrm{mg} \mathrm{kg}^{-1}\right.$ may be recommended against resistant isolates) and $7 \mathrm{mg} \mathrm{kg}^{-1}$ is indicated for AAT due to T. brucei and for surra, administered by intramuscular or subcutaneous injection (Connor, 1992). The common practice of administering $3.5 \mathrm{mg} \mathrm{kg}^{-1}$ of the drug to treat $T$. b. evansi infections is considered an underdosing, and this misuse may have contributed to the emergence of resistant strains in South-East Asia (Desquesnes et al. 2013a). The fact that higher doses appear to be needed to treat T. brucei group 
trypanosomes, in spite of these parasites being more sensitive to the drug, probably relates to their wider tissue dispersal compared with $T$. congolense and $T$. vivax, underlining the key role of host pharmacokinetics.

Diminazene is only applied as a curative agent and is not used for prophylaxis, as it is rapidly metabolized and excreted (Peregrine and Mamman, 1993). After rapid absorption (the peak blood level is reached within $1 \mathrm{~h}$ of dosing), elimination follows a biphasic or triphasic behaviour depending on the animal species and formulation; elimination halflife values following intramuscular administration varied from $11-19 \mathrm{~h}$ in sheep and goats, to 74 to $>200 \mathrm{~h}$ in cattle (Mamman et al. 1993; Peregrine and Mamman, 1993; Mdachi et al. 1995; El Banna et al. 1999). Cattle excrete diminazene mainly in the urine, together with two main metabolites: $p$-aminobenzamidine and $p$-amino-benzamide (Kellner et al. 1985). Diminazene residues may persist for several weeks in the edible tissues of cattle and other food-producing animals, especially in the liver and kidney, whereas the drug levels in milk peak at $6 \mathrm{~h}$ and fall to below detection limits after $48 \mathrm{~h}$ (FAO, 1990). For this reason it is advised that cattle and sheep destined for human consumption are subject to a 21-35 days pre-slaughter withdrawal (discard) from drug, while a 3-day milk discard period is recommended (FAO, 1990; Peregrine and Mamman, 1993); however, productspecific withdrawal periods as given on product labels should be adhered to.

The trypanocidal mode of action of diminazene has not been completely elucidated. The compound binds the minor groove of the DNA at AT-rich sites (Wilson et al. 2008). In trypanosomes, the kDNA is a known target of the drug, and kDNA binding can cause inhibition of replication and kDNA loss (Shapiro and Englund, 1990), possibly exacerbated by an inhibitory effect on mitochondrial type II topoisomerase (Portugal, 1994). It had long been believed that loss of the kinetoplast might not be sufficient to kill trypanosomes, as viable dyskinetoplastic strains do occur naturally and also can be produced artificially in the laboratory (Schnaufer et al. 2002). However, the discovery in laboratory generated-dyskinetoplastic T. b. brucei of a compensating mutation in the nuclear genome-encoded $\gamma$-subunit of the mitochondrial ATP synthase (Dean et al. 2013) meant that the kinetoplast has been resurrected as the potential drug target of diminazene. These dyskinetoplastic lines do indeed show significant in vitro resistance to diamidines (including diminazene aceturate) and phenanthridines (Gould and Schnaufer, 2014). Furamidine (DB75), a closely related diamidine, whose fluorescent properties enabled tracking of its cellular distribution, was shown to bind to T. b. brucei $\mathrm{kDNA}$ and nuclear DNA in situ, and also to accumulate in other organelles identified as acidocalcisomes (Mathis et al. 2006). The compound was also shown to interfere with the mitochondrial membrane potential (Lanteri et al. 2008). Interestingly, it has been suggested that diminazene can also modulate the host immune response by dampening pro-inflammatory cytokines and excessive immune activation, which might also influence the in vivo effects of the drug (Kuriakose et al. 2012).

Chemically, diminazene is an aromatic diamidine made of two benzamidine moieties linked by a triazene bridge. Due to its charged nature, diminazene can only cross membranes via specific carriers and this has three important consequences: (a) the drug is not active on CNS infections as it cannot cross the blood-brain barrier; (b) the compound is selectively toxic to trypanosomes, as they express transporters that specifically accumulate diminazene; and (c) trypanosomes may become resistant to the drug by losing these transporters or their activity. As mentioned above, diminazene uptake in $T$. brucei mainly occurs via an aminopurine transporter called P2 or TbAT1, which is also implicated in the uptake of the related diamidine pentamidine and the melaminophenyl arsenical melarsoprol, two drugs licensed for HAT (Carter et al. 1995; Barrett and Fairlamb, 1999; De Koning, 2008). Diminazene uptake into $T$. bruce $i$ is fast, with a $K m$ of $0.45 \mu \mathrm{M}$ and a $V_{\max }$ of $0.049 \mathrm{pm} 10^{7}$ cells $^{-1} \mathrm{~s}^{-1}$ (De Koning et al. 2004) and is inhibited by pentamidine and adenosine, the main physiological substrate of this carrier. Loss of P2/TbAT1 activity was shown to cause diminazene resistance in $T$. b. brucei (Matovu et al. 2003), T. b. equiperdum (Barrett et al. 1995; Stewart et al. 2010) and T. b. evansi (Witola et al. 2004). Another gene, named TeDR40, has also been implicated in resistance in $T$. b. evansi (Witola et al. 2005). However, using that gene to search for orthologues in other trypanosomatids at the TriTrypDB database (www.tritrypdb.org), indicates that it is actually a variant surface glycoprotein (VSG) gene, part of the parasite's system of antigenic variation whereby it avoids host immunity. It is possible that, in the process of selection of resistance, the parasites switched expression of a VSG gene independently of the resistance selection, which explains the massive increase in expression of that gene.

The application to $T$. brucei of a genome-wide RNA interference target sequencing (RIT-seq) screen, where any gene whose loss of function is identified by reduced drug sensitivity, was able to identify additional plasma membrane proteins (P-type $\mathrm{H}^{+}$-ATPases), as well as a putative protein phosphatase, that were linked to the action of the related diamidine pentamidine (Alsford et al. 2012). The HAPT1/TbAQP2 carrier (De Koning, 2001b), encoded by the TbAQP2 gene (Baker et al. 2012), has a key role in uptake of 
pentamidine and the melaminophenyl arsenicals in $T$. brucei, although its role in diminazene uptake is less pronounced (Teka et al. 2011; Munday et al. 2014) and loss of P2/TbAT1 alone is sufficient to give high level of resistance to this latter drug (Matovu et al. 2003). It has recently been proposed that $T b \mathrm{AQP} 2$ acts as a receptor for pentamidine, with high affinity, and its uptake then occurs via receptor-mediated endocytosis (Song et al. 2016); further work is needed to confirm or refute this hypothesis, although other evidence points to pentamidine actually entering through the channel, enabled by a unique selectivity filter and the high degree of flexibility of the pentamidine chain (Munday et al. 2014, 2015a).

Trypanosoma congolense appears to lack a functional equivalent of TbAQP2. A putative P2/ TbAT1-type transporter, TcoAT1, was identified in $T$. congolense and a particular allele proposed to be associated with diminazene resistance (Delespaux et al. 2006). This conclusion was curious, given that the so-called resistance allele was not always associated with resistant form parasites isolated in one region (Delespaux et al. 2006) and was also abundant in areas where diminazene had not been used (Chitanga et al. 2011). Furthermore, TcoAT1 is not the orthologue of $T b A T 1$, instead corresponding to a related, but distinct, member of the nucleoside transporter family (Munday et al. 2013). Its heterologous expression has proven that the encoded protein does not enable diminazene uptake, instead facilitating the uptake of adenosine and inosine (Munday et al. 2013). Hence, it can be definitively ruled out that the gene misnamed $T c o A T 1$ has any role in diminazene uptake, action, or resistance.

Diminazene resistance is generally believed to be difficult to produce experimentally in $T$. congolense (in contrast to T. brucei). High levels of resistance to the drug were obtained in mice infected with T. b. evansi, but only when using immunocompromised animals, a result which stresses the importance of the link between immunity and chemotherapy, as the efficacy of trypanocides appears to be reduced by immunosuppression, hence favouring development of resistance (Osman et al. 1992). In vitro experiments with $T . b$. brucei and T.b. evansi demonstrated that a shared mechanism of internalization accounts for the cross-resistance between diminazene and other diamidines as well as melaminophenyl arsenicals (melarsoprol and melarsomine) (Matovu et al. 2003). By contrast, no cross-resistance was observed with other chemically unrelated compounds including suramin or quinapyramine. A degree of cross-resistance has been observed between isometamidium and diminazene in $T$. brucei group trypanosomes, although the functional basis of this is not clear (Zhang et al. 1991; Witola et al. 2004).

\section{Homidium salts}

Homidium bromide or ethidium bromide, also available as a chloride salt Novidium $^{\circledR}$, Table 1), was introduced for field use in 1952, as an improvement to previous phenanthridine-based trypanocidal agents (Wainwright, 2010). It is widely used in Africa to treat $T$. congolense and $T$. vivax infections in cattle, sheep and goats, in spite of its proven mutagenic and possible carcinogenic properties as a DNA intercalator (Sutcliffe et al. 2014). Due to its potential toxicity, the use of homidium is today highly discouraged (Sutcliffe et al. 2014). Widespread resistance to the drug in the 1960s and 1970s reduced its usage. Today, the number of doses of homidium used annually is reported to be down to around $10 \%$ of the total African trypanocide market, but this value may be a significant underestimate of its real use (Frans van Gool, personal communication, 2015).

Although used as a curative drug, homidium also possesses chemoprophylactic properties, but these are less pronounced than those of isometamidium (see subsection Isometamidium chloride below). For both purposes, homidium is administered at the dose of $1 \mathrm{mg} \mathrm{kg}^{-1}$ by a single, deep intramuscular injection (Peregrine, 1994). Homidium excretion is faster than isometamidium, its serum concentration declining rapidly over the first $24 \mathrm{~h}$ following both intravenous and intramuscular injection at a standard dosage (Murilla et al. 1999). Elimination halflife ranged from $178 \mathrm{~h}$ in Boran cattle to $488 \mathrm{~h}$ in Friesian cattle following intramuscular injection (Murilla et al. 1999). However, low levels of the drug $\left(0 \cdot 1-0 \cdot 3 \mathrm{ng} \mathrm{mL}^{-1}\right)$ do persist in circulation for several weeks when given intramuscularly, providing an 8-17-week prophylaxis period (Dolan et al. 1990; Murilla et al. 1999). Homidium has an extensive extravascular distribution and accumulates predominantly in the liver and the kidneys (Murilla et al. 1996), a factor which presents some risk in products from treated animals destined for human consumption. Homidium can be used as sanative pair with diminazene, but not with isometamidium, where the shared phenanthridine core underlies cross-resistance (Peregrine et al. 1997).

Intracellular localization of homidium can be monitored by microscopy, exploiting the intrinsic fluorescence of the compound. Work on T. brucei showed that homidium localizes in the nucleus and the kinetoplast of treated trypanosomes (Cox et al. 1984; Boibessot et al. 2002). Treatment with the drug induces dyskinetoplasty in a similar way to other phenanthridines and diamidines (Riou et al. 1980; Shapiro and Englund, 1990) and disruption of genome function has long been believed to underlie its trypanocidal effects. Indeed, it was found that homidium blocks both kinetoplast and nuclear DNA replication in $T$. brucei by distorting and changing the double helix topology (Roy Chowdhury et al. 
2010). The inhibition of minicircle replication and, consequently, loss of the kinetoplast network, was found to be the primary killing mechanism at low doses $\left(0.02 \mu \mathrm{g} \mathrm{mL}^{-1}\right)$, but at higher doses homidium was also shown to affect nuclear DNA, which could account for its ability to kill dyskinetoplastic trypanosomes (Roy Chowdhury et al. 2010). The reason for the initial targeting of the kinetoplast over the nucleus is believed to be the result of the preferential accumulation of lipophilic cations (such as homidium) in the mitochondrion, as shown with other experimental trypanocides (Lanteri et al. 2008; Ibrahim et al. 2011; Alkhaldi et al. 2016). The mechanism of resistance to homidium is not known, but it is likely to be similar to that of the related compound isometamidium.

\section{Isometamidium chloride}

Isometamidium chloride hydrochloride is a hybrid phenanthridine with amphiphilic and cationic properties, synthesized by coupling homidium with the diazotized $p$-aminobenzamide moiety of diminazene, modified with the amidine group in the meta position (see Table 1 for structures). It has both curative and prophylactic properties and, since its launch in the 1960s, it has remained the only drug available for chemoprophylaxis of AAT, after quinapyramine was discontinued due to problems linked to toxicity and, particularly, the induction of multi-drug resistance (Peregrine, 1994; Geerts and Holmes, 1998). The veterinary formulations are typically a mixture of four phenanthridine compounds: isometamidium chloride hydrochloride [8-(3-mamidinophenyl-2-triazeno)-3-amino-5-ethyl-6-phenylphenanthridinium chloride hydrochloride], the positional red isomer [3-(3-m-amidinophenyl-2triazeno)-8-amino-5-ethyl-6-phenylphenanthridinium chloride hydrochloride], the blue isomer [7- $(m-$ amidinophenyldiazo)-3,8-diamino-5-ethyl-6-phenylphenanthridinium chloride hydrochloride], and the disubstituted compound [3,8-di(3-m-amidinophenyltriazeno)-5-ethyl-6-phenylphenanthridinium chloride dihydrochloride]. A protocol for their individual purification from the mixture and a detailed structural analysis of each compound were described in a recent publication (Igoli et al. 2015). In commercial products isometamidium is the principal component (guidelines establish it must be at least $55 \%$ of the total material), with the other components accounting for less than $40 \%$ (Sutcliffe et al. 2014). As the in vitro and in vivo trypanocidal activity on $T$. congolense is lower for the red and blue isomer it is paramount that the product composition follows strict quality standards (Sahin et al. 2014). The disubstituted compound has poor trypanocidal activity but it has a good prophylactic effect, possibly because it can act as a pro-drug that is cleaved to isometamidium in vivo (Sahin et al. 2014).
Isometamidium is used primarily to treat and prevent $T$. congolense and $T$. vivax infections in livestock in Africa. Its activity against $T$. brucei spp. is less marked, but this drug can also be utilized against some $T$. $b$. evansi strains, although not when these have reached the CNS, as the compound does not cross the blood-brain barrier. The drug is administered to cattle at single doses of $0 \cdot 25-1 \cdot 0$ $\mathrm{mg} \mathrm{kg}^{-1}$ for cure, and at doses of $0 \cdot 5-1 \mathrm{mg} \mathrm{kg}^{-1}$ for prophylaxis (Leach and Roberts, 1981). The dosage for $T$. $b$. evansi infections is generally $1-2 \mathrm{mg} \mathrm{kg}^{-1}$, but in horses it is recommended not to exceed $0 \cdot 5$ $\mathrm{mg} \mathrm{kg}^{-1}$ due to toxicity issues (Uilenberg, 1998; Desquesnes et al. 2013a). Multiple intramuscular administrations of isometamidium can cause severe fibrous lesions, hence damaging the carcass and meat quality from livestock. Intravenous administration has been successfully used to abrogate muscular damage, but it has been suggested that this could result in compromised prophylactic activity, due to the lack of a drug depot at the injection site (Dowler et al. 1989; Munstermann et al. 1992). The duration of prophylactic activity following intramuscular administration in cattle is typically $2-3$ months and may be up to 6 months, but can vary greatly, depending on the formulation and dosage used and on the parasite strain, as well as on other factors, including susceptibility of the particular breed and its general health status (Toro et al. 1983; Kinabo and Bogan, 1988).

Isometamidium plasma concentrations reach their peak within $1 \mathrm{~h}$ after administration and then fall relatively quickly during the first week post-treatment and thereafter more gradually (Kinabo, 1993; Eisler et al. 1994). Three months after cattle had been injected, the circulating drug concentration was measured at $0.75 \mathrm{ng} \mathrm{mL}^{-1}$ (Eisler et al. 1994). This study showed that the serum concentration fits a bi-exponential model, with half-life of approximately 25 days for the second phase in cattle (Eisler et al. 1994), while another study (Eisler, 1996) indicated an elimination half-life of 9-19 days. In sheep and goats isometamidium appears to be eliminated more rapidly than in cattle (Wesongah et al. 2004). The drug accumulates in the liver, kidneys and spleen as well as at the injection site, and from here it is slowly released to the plasma exerting its prophylactic activity (Kinabo and Bogan, 1988). Persistence of isometamidium residues is much longer than for diminazene. For this reason, a withdrawal period of 30 days was established for consumption of produce from cattle treated with the drug (FAO, 1990), although in practice the withdrawal (discard) period is always product-specific. Excretion occurs mainly via bile and levels in cattle milk are generally very low (Kinabo, 1993).

Isometamidium may be used as part of a sanative pair with diminazene, the two drugs being used sequentially to minimize the risk of resistance 
development (Leach and Roberts, 1981; Peregrine, 1994). Despite this recommendation, there are multiple reports of field isolates, from many African countries, indicating isometamidium resistance, particularly in $T$. congolense but also in $T$. bruce $i$ species and $T$. vivax, sometimes detailing cross-resistance with diminazene (Ainanshe et al. 1992; Clausen et al. 1992; Codjia et al. 1993; Afewerk et al. 2000; Sinyangwe et al. 2004; Mamoudou et al. 2008). However, other reports found no cross-resistance (e.g. Gray et al. 1993; Joshua et al. 1995) and we conclude that cross-resistance does not necessarily occur, but may be a consequence of the level of resistance that has been established, whereas in other cases resistance to both drugs may have been induced separately. In addition, the chance of cross-resistance developing may be different for the various animal trypanosome species, given their known differences in biochemical physiology and drug transport.

By taking advantage of isometamidium's intrinsic fluorescence, accumulation in the kinetoplast was observed (Wilkes et al. 1995; Boibessot et al. 2002). Although closely related to the intercalating phenanthridine homidium, isometamidium is not known to be carcinogenic, and was reported to bind kDNA with an unconventional 'sideways' geometry (Dougherty and Waring, 1982). Its high affinity for the kDNA might underlie its trypanocidal activity. Linearization of kDNA minicircles in $T$. b. equiperdum following interaction of the drug with the kinetoplast was observed (Shapiro and Englund, 1990). Moreover, naturally occurring dyskinetoplastic T. b. evansi (Brun and Lun, 1994) and in vitro-generated $T$. b. brucei lacking a functional kinetoplast (Gould and Schnaufer, 2014) are highly resistant to the drug. Efficacy against some $T$. b. evansi strains might relate to these parasites retaining $\mathrm{kDNA}$ (albeit dispersed in dyskinetoplastidy) while others are akinetoplastic (i.e. retain no kDNA at all) and may be less susceptible to the drug. However, the drug would still accumulate preferentially in the mitochondrion, as the mitochondrial membrane potential is unaffected by the loss of the kinetoplast in cells carrying a compensatory mutation in the $\gamma$-subunit of the $\mathrm{F}_{1} \mathrm{~F}_{0}$-ATP synthase (Dean et al. 2013), providing a driving force for cations. A mutation in this ATP synthase subunit is sufficient to cause a substantial level of isometamidium and homidium resistance, although further drug pressure was shown to increase this even further. Interestingly, this very high level of resistance is indeed associated with a loss of mitochondrial membrane potential, preventing further isometamidium accumulation in this organelle (Eze et al. 2016).

Despite possessing the recognition motif for the P2/TbAT1 transporter and despite being a highaffinity inhibitor of this carrier (De Koning, 2001a), the internalization of isometamidium depends at most partially on this route (Delespaux and de Koning, 2007). Passive diffusion across the membrane may be feasible but is not likely, given the two positive charges on the molecule and partial characterization of isometamidium transport, linking drug resistance, at least in part, to reduced uptake (Sutherland et al. 1992; Wilkes et al. 1995, 1997). High-throughput RIT-seq (Baker et al. 2015) failed to identify involvement of any of the receptor-mediated endocytosis pathways as previously identified for suramin (see subsection Suramin sodium below) using this approach (Alsford et al. 2012), although alternative endocytic routes could not be ruled out.

Resistance to isometamidium is encountered in the field. In T. congolense a mechanism behind resistance was proposed to relate to diminished mitochondrial membrane potential (Wilkes et al. 1997). This, in turn, would diminish the accumulation of drug in the mitochondrion, having a net effect of reduced uptake at the plasma membrane, presumably due to rapid equilibration of intracellular and extracellular concentrations when the mitochondrial sink is lost. Active extrusion by plasma membrane transporters has also been proposed (Sutherland and Holmes, 1993). A recent application of the RITseq approach, conducted on $T$. brucei, identified mutations to many subunits of the vacuolar ATPase (found in the lysosomes and acidocalcisomes), in the trafficking protein AP-3 (an adaptin that mediates delivery of proteins to lysosomerelated organelles) and in EMC (an ER membrane complex) that reduced drug activity, potentially contributing to dug resistance (Baker et al. 2015). Secondary loss of kDNA was found to be possible once vATPase and AP-3 subunits are lost from the cells, pointing to an intriguing, but as yet illdefined, interaction between the vacuolar system and mitochondrion. The fact that kDNA is lost in cells selected for resistance to isometamidium was classically interpreted to point to its role as target. However, the discovery that kDNA loss can occur as a consequence of changes to the vacuolar system complicates this interpretation.

\section{Quinapyramine sulphate}

Quinapyramine sulphate was developed from the early trypanocide Surfen C (Curd and Davey, 1950) and came into use around 1950. The compound was applied to treat cattle infected with trypanosomes until 1976, when it was withdrawn from many areas due to emergence of widespread resistance (Connor, 1992). The drug was subsequently reintroduced in 1984 to treat $T$. b. evansi in camels and horses (Peregrine, 1994), and is still used today (Ranjithkumar et al. 2014). In horses with acute infections of $T$. brucei spp. quinapyramine is 
considered the most effective treatment $\left(5 \mathrm{mg} \mathrm{kg}^{-1}\right.$ via subcutaneous injection), although the drug induces severe but transient side effects in these animals (Auty et al. 2008). The prosalt form of quinapyramine (a mixture of the soluble sulphate and the insoluble chloride salts) was the first prophylactic drug available for animal infections. A $7 \cdot 4 \mathrm{mg}$ $\mathrm{kg}^{-1}$ dose of this prosalt suspension has both a curative and a prophylactic (up to 4 months) effect on $T$. b. evansi infections in horses and camels (Williamson, 1970).

Quinapyramine is a quinoline pyrimidine (Table 1) and, as isometamidium and diminazene, a dication at physiological $\mathrm{pH}$ (homidium is monocationic). As seen for the other charged trypanocides, quinapyramine is unable to cross the bloodbrain barrier, which explains its failure to cure $T$. b. evansi infections in equids when the CNS is affected (Ranjithkumar et al. 2014). However, it is important to note that some cationic trypanocides do penetrate the blood-brain barrier, the clearest example being compound DB829 (Wenzler et al. 2013). Pentamidine has actually been used to treat 'early-late stage' HAT (Doua et al. 1996) but its movement across the blood-brain barrier is counteracted by active efflux mechanisms, including $\mathrm{P}$ glycoprotein and multi-drug resistance transporters (Sanderson et al. 2009).

Plasma levels of quinapyramine decline rapidly after dosing and, in the case of the prosalt, its persistence is probably due to slow release from the subcutaneous depot formed at the injection site (Spinks, 1950). Quinapyramine accumulates in the liver and kidneys, where its concentration remains high for weeks and can cause organ-specific toxicity. Excretion occurs mainly via urine (Spinks, 1950).

Quinapyramine's mode of action remains unknown. Hypotheses include the interference with nucleic acid synthesis and inhibition of cytoplasmic ribosomes (and, therefore, protein synthesis) (Newton, 1962, 1966). However, its dicationic/ aromatic nature would strongly suggest a mitochondrial accumulation, as with the phenanthridines and bis-benzamidines.

Trypanosoma congolense and T. b. evansi lines resistant to the drug can easily be obtained by in vivo selection in mice (Ndoutamia et al. 1993; Liao and Shen, 2010). As quinapyramine resistant T. congolense trypanosomes show cross-resistance to isometamidium, homidium and diminazene, the use of this compound to treat infections in cattle is not recommended (Peregrine et al. 1997). Given the lack of cross-resistance between diminazene and homidium, the fact that quinapyramine is cross-resistant to both is intriguing. Although the mechanism underpinning quinapyramine resistance remains unknown, it is likely that all these trypanocides have a mitochondrial target and that any single change that dramatically reduces the mitochondrial membrane potential, or the loss of organic cation carriers in the inner mitochondrial membrane, could result in resistance to all of them.

\section{Suramin sodium}

Suramin sodium is a symmetrical polyanionic sulfonated naphthylamine (Table 1). It is the oldest trypanocide still in use, having been introduced in 1921 for the treatment of surra in camels and replacing the then-standard treatment of intravenous tartar emetic (potassium antimonyl tartrate) (Uilenberg, 1998). A single dose of $6-10 \mathrm{~g}$ of suramin sodium per camel was described as $100 \%$ effective (Bennett, 1930). Suramin is also the standard treatment for equine trypanosomiasis ( $T$. brucei spp.), being more effective than diminazene and less toxic than quinapyramine (Williamson, 1970). The current treatment for camels and horses is 10 $\mathrm{mg} \mathrm{kg}^{-1}$, administered intravenously. Intramuscular administration is avoided as it causes intense local irritation. Suramin has further been used for cure and prophylaxis of onchocerciasis and other microfilarial infections including Brugia pahangi (Delespaux and de Koning, 2007), as well as for the treatment of early stage HAT since 1922 (Apted, 1970). Although suramin is effective against $T$. b. gambiense (Knobloch et al. 1984; Pepin and Khonde, 1996), it is mostly used against HAT due to $T$. $b$. rhodesiense, for which it is still available today (Voogd et al. 1993), whereas it was replaced with pentamidine for the form due to T. b. gambiense. Although the drug has good efficacy against $T$. simiae in pigs (Stephen, 1966; Williamson, 1970), it is relatively ineffective against $T$. congolense and $T$. vivax (Leach and Roberts, 1981), presumably due to the aforementioned differences in biochemical physiology that distinguish $T$. brucei group organisms from these other species.

Old work showed that suramin can be used as a prophylactic agent when administered subcutaneously as an insoluble complex with one of the cationic trypanocides (e.g. with quinapyramine, in a 1:3 molecular proportion, reflecting the six negative charges of suramin $v s$ the two cationic charges of quinapyramine), resulting in 3-6 months protection at $40 \mathrm{mg} \mathrm{kg}^{-1}$ of quinapyramine in pigs (Williamson, 1970) and $>160$ days protection in cattle (Williamson and Desowitz, 1956). This approach could be effective for the eradication of $T$. b. gambiense in pigs, which are reportedly acting as reservoir hosts of this species (Mehlitz et al. 1982). Complexes of suramin with homidium, quinapyramine and prothidium also gave protection in experimental infections in cattle (Desowitz, 1957).

The pharmacokinetic parameters of suramin in animals (Kinabo, 1993) have not been subject to the same extensive characterization as occurred in humans, where the compound has also been trialled 
for the treatment of AIDS and cancer (Barrett et al. $2007)$. Most of the drug ( $>99 \%$ ) binds to plasma proteins yielding a slow clearance. The terminal half-life in humans ranges between 40 and 50 days or more, depending on the infusion protocol applied (Jodrell et al. 1994). This slow clearance underpins limited (i.e. several weeks) prophylactic action in animals too when the drug is used on its own. Suramin does suppress infection, but is dependent on the host's immune response to be fully effective (Leach and Roberts, 1981). Because of its large molecular size and highly anionic nature, suramin does not cross the blood-brain barrier.

Suramin strongly binds to human serum proteins and various trypanosome enzymes by electrostatic interaction (Voogd et al. 1993). The drug was proposed to enter trypanosomes via receptor-mediated uptake bound to LDL and to accumulate in the lysosome (Vansterkenburg et al. 1993). This hypothesis, however, looked doubtful after it was demonstrated that in T. brucei (procyclic form at least) suramin and LDL uptake are not coupled (Pal et al. 2002). A definitive mode of action for the compound has not been determined. Fairlamb and Bowman proposed that suramin curbs glycolytic ATP production in $T$. brucei by inhibiting glycerol-3-phospate oxidase and $\mathrm{NAD}^{+}$-dependent glycerol-3-phosphate dehydrogenase (Fairlamb and Bowman, 1980). However, being highly charged, suramin binds many enzymes when assayed and a multitude of putative targets have been proposed (Gutteridge, 1985), including 6-phosphogluconate dehydrogenase, of the pentose phosphate pathway, of which it is a competitive inhibitor (Hanau et al. 1996). More recently, a RIT-seq screen in bloodstream $T$. brucei identified 28 genes that contribute to suramin action, including: a surface glycoprotein family (ISG75), which appears to be the ligand to which the drug binds; cathepsin L, believed to release the drug from ligand within the lysosomal system; a number of deubiquitinating enzymes and various proteins involved in the endocytic pathway (Alsford et al. 2012). It appears that inhibiting uptake of suramin, or its normal passage through the endocytic pathway following binding to a specific receptor, is sufficient to render parasites resistant to the drug, although it remains unknown how suramin kills once accumulated intracellularly.

Extensive use of the compound in the first half of the 20th century resulted in emergence of widespread resistance in T. b. evansi in Africa (Boid et al. 1989; El Rayah et al. 1999) and South-East Asia (Gill, 1971; Zhou et al. 2004), in some cases leading to withdrawal of suramin as a treatment (E1 Rayah et al. 1999). However, even in the absence of drug pressure, the resistance phenotype has persisted in the field, as found for some Sudanese T. b. evansi strains (El Rayah et al. 1999). Stability of the suramin resistance phenotype was also observed in T. brucei lines generated in vitro (Scott et al. 1996) and in T.b. evansi parasites selected in mice (Mutugi et al. 1994). However, the drug was effective against $T . b$. evansi isolates in Brazil, where it had not been used (Faccio et al. 2013).

\section{Melarsomine dihydrochloride}

An early reported case of an attempt to cure an animal afflicted with trypanosomiasis was that of Dr David Livingstone, the Scottish missionary whose travels in Southern Africa in the mid-19th century were exceptionally well recorded. In a letter to the British Medical Journal in 1858 he described the use of arsenic oxide (Fowler's solution) to treat a case of 'fly disease' in a horse (Livingstone, 1858). Although the treated horse was not cured, there was a temporary relief in symptoms. Over 50 years later, once the trypanosome had been implicated, H. W. Thomas and A. Breinl, and then P. Ehrlich, revisited arsenic chemistry to seek trypanocides in the early days of chemotherapy (Williamson, 1970). By the 1950s melarsoprol had been introduced for the treatment of late-stage HAT; the drug was created by coupling of melarsen oxide to 2,3-dimercaptopropanol (Steverding, 2010). The formulation displayed diminished toxicity while retaining potent trypanocidal activity.

Melarsomine dihydrochloride (Table 1) is a melamino-phenylarsine, synthesized by linking melarsen oxide (Barrett et al. 2007) to two equivalent of cysteamine (Berger and Fairlamb, 1994). The compound has improved aqueous solubility over melarsoprol. It was introduced to the market in 1992 and is the latest addition to the veterinary trypanocidal list. The drug (Immiticide ${ }^{\circledR}$ ) is also used in the treatment of heartworms in dogs, where it kills adult worms (McCall et al. 1994), albeit with a low margin of safety. It is registered for use against $T$. b. evansi in camels at a dose of $0.25 \mathrm{mg} \mathrm{kg}^{-1}$, but it has also been evaluated and proven efficacious against $T$. $b$. evansi infections in cattle (Desquesnes et al. 2011), goats (Gutierrez et al. 2008) and horses (Tamarit et al. 2010), although at higher dosages than that applied to camels (i.e. $0.5 \mathrm{mg}$ $\mathrm{kg}^{-1}$ or above). Melarsomine also proved curative in cattle infected with $T . b$. evansi strains resistant to suramin (Payne et al. 1994). Moreover, treatment regimens with both 0.25 and $0.5 \mathrm{mg} \mathrm{kg}^{-1}$ of the drug were proven effective in curing acute and chronic $T$. b. equiperdum infections in horses, resulting in a reduction of neurological symptoms (Hagos et al. 2010) and offering a possible treatment for these infections. Side effects to the drug are usually mild (salivation, lacrimation, muscle tremors, increased gut motility and frequent urination), but a severe adverse reaction has also been documented (Berlin et al. 2010). Reports of neurological sequelae in dogs (Hettlich et al. 2003), albeit perhaps not 
analogous to the reactive encephalopathy associated with melarsoprol treatment of humans (Blum et al. 2001), are notable. Should the reduced neurotoxicity of melarsomine be replicated in man it might be considered as a replacement for melarsoprol, although it is doubtful that comparative clinical trials of the two arsenicals would receive ethical clearance, especially since melarsoprol is being phased out in favour of nifurtimox-eflornithine combination therapy (Simarro et al. 2012). The paucity of compounds that kill adult filarial worms is of note too, and, should the safety profile of melarsomine be acceptable, it could be considered for use against the human filariases.

The mode of action of melarsomine is unknown. As for other trypanocidal arsenicals, the disruption of the thiol-redox balance is a possible mechanism (Fairlamb, 2003). The drug (or, rather, its metabolite melarsen oxide) enters T. bruce $i$ via the same P2/ TbAT1 adenosine nucleoside transporter (Carter and Fairlamb, 1993; De Koning and Jarvis, 1999) and TbAQP2 (Munday et al. 2014) that carry other melaminophenyl arsenicals and the diamidine trypanocides. Selective uptake probably accounts for most of the selective toxicity of the arsenicals (Baker et al. 2013). Reduction of P2/TbAT1 activity is a known reason behind onset of cross-resistance between the compounds that enter via this route: trypanosomes of the $T$. brucei group resistant to melarsomine are often also less sensitive to diamidines and other arsenical drugs as melarsoprol, but not to suramin (Zhang et al. 1991; Pospichal et al. 1994). In vitro and in vivo selected melarsomine-resistant T. b. evansi (Suswam et al. 2001) revealed that the decrease in P2/TbAT1 transporter activity was linked both to reduced transporter expression and changes in binding properties (Suswam et al. 2003). In a T. b. brucei strain selected for melarsomine resistance in mice the $T b A T 1$ gene was still present but its transcript was lost (Stewart et al. 2010). The lack of authentic orthologues of TbAT1 and TbAQP2 in T. congolense and T. vivax (see subsection Diminazene aceturate above) may explain why the drug is less potent against these parasites.

DRUG RESISTANCE IN THE FIELD: DEFINITION AND EXTENT OF THE PROBLEM

Drug resistance is suspected when treatment failure occurs using standard drug dosages. However, in the field, this interpretation can be erroneous, as treatment failure can result from many factors other than the parasite's increased tolerance to drugs. For example, the presence of parasites in treated animals could correspond to a new infection rather than to recrudescence, particularly in areas of high challenge (Rowlands et al. 2001). Using microsatellite DNA markers to strain type $T$. congolense from cattle in Ethiopia following treatment with diminazene, essentially equal occurrences of new infection $(40 \%)$ and actual relapse $(37 \cdot 5 \%)$ were proposed (Moti et al. 2015). Other causes of treatment failure not linked to true drug resistance could be related to the poor health state of the animal (e.g. malnutrition, immunosuppression, concurrent infections), or to incorrect drug use (e.g. irregular treatment or prolonged intervals between treatments), or to under-dosage. The latter can result from poor drug quality (either due to inappropriate storage or to the use of counterfeit products) (Sutcliffe et al. 2014), or from incorrect drug usage (wrong dilution, use of unsterilized water or erroneous dosage due to inaccurate estimation of the animal weight) (Van den Bossche et al. 2000; Grace et al. 2009). For phenanthridines, in particular isometamidium, the adverse reaction which often appears at the injection site might possibly alter drug absorption and diminish the levels of drug in circulation (Kinabo, 1993), thus determining under-dosage. It is widely believed that under-dosing could represent a major determinant in drug resistance development in the field through parasite exposure to sub-curative drug concentrations (Leach and Roberts, 1981). A similar phenomenon could derive from failure to comply with strict dose timing, which could lead to periods where sub-prophylactic drug levels are present (Leach and Roberts, 1981). Moreover, as a mutagen, homidium might also directly contribute to resistance appearance through induction of mutations in parasites that are then selected under drug pressure. Constant parasitological monitoring is necessary to distinguish treatment failure from appearance of true resistance.

In the previous section, we have outlined that there are issues associated with selected resistance to each of the drugs used against the animal trypanosomiases. Cases of resistance to veterinary trypanocides started to be reported in the field soon after their introduction, and their numbers have been increasing ever since (Delespaux et al. 2008b). A review of available literature in 2008 reported loss of efficacy of the available AAT trypanocides in at least 17 African countries (Delespaux et al. 2008b). Available data, in 2001, indicated that resistance to isometamidium was more widespread than resistance to diminazene (Geerts et al. 2001), however, this may no longer be so, as prevalence of resistance may change substantially over a few years (Delespaux et al. 2008a). Treatment failure against $T$. congolense and T. vivax infections with either of these drugs has been observed in both West (Kupper and Wolters, 1983; Pinder and Authie, 1984; Knoppe et al. 2006; Mungube et al. 2012; Vitouley et al. 2012) and East Africa (Mbwambo et al. 1988; Chitambo and Arakawa, 1992a; Dagnachew et al. 2015; Moti et al. 2015). More worryingly, strains of $T$. congolense resistant to both isometamidium and diminazene have been 
detected in several locations, including Cameroon (Mamoudou et al. 2008), Burkina Faso (Clausen et al. 1992), Ethiopia (Codjia et al. 1993; Afewerk et al. 2000; Moti et al. 2012), Somalia (Ainanshe et al. 1992) and Zambia (Sinyangwe et al. 2004), rendering their use as a sanative pair inoperative. These multiple resistant stocks might be the result of separate selection processes for the two drugs, as crossresistance between diminazene and isometamidium has been considered a rare phenomenon.

Drug resistance to animal trypanocides has also been reported from outside of Africa. For example, $T$. vivax strains refractory to diminazene were identified in South America, where the compound is the first line drug to treat these infections (Desquesnes et al. 1995; Cadioli et al. 2012). Diminazene treatment failure against $T . b$. evansi infections in horses and mules in Thailand has also been reported, following decades of use ('Tuntasuvan et al. 2003). Trypanosoma b. evansi strains resistant to suramin (Zhou et al. 2004) and quinapyramine (Zhou et al. 2004; Liao and Shen, 2010) have been reported in China as well as in Africa (El Rayah et al. 1999).

\section{TESTS FOR RESISTANCE DETECTION}

\section{In vivo methods}

Because of the confounding factors that can cause treatment failures, outlined above, methods to assess true resistance are crucial. However, reliable tests have been relatively difficult to establish for widespread use in settings where AAT is endemic. Methods such as the 'block treatment' approach (Delespaux et al. 2008b) have been proposed to enable identification of probable resistance in the field, whereby cattle in a particular location are split into control and treated groups and followed to first detection of parasitaemia. Broadly, the presence of resistance is measured by comparing time to parasite detection in treated $v s$ the untreated controls (Eisler et al. 2000): the closer to the control group, the more likely the presence of resistance. However, although there are logistical advantages to such tests (e.g. no requirement for parasite isolation), they still require considerable investment in time and numbers of cattle involved (typically revisits every two weeks for 10-14 weeks, suggested group sizes of 30-80 animals), and the results are only indicative of resistance. Confirmatory trypanocide efficacy studies against veterinary trypanosomes still rely primarily on infection and treatment experiments in the natural hosts or in laboratory animals (i.e. rodents), where parasite clearance from blood following treatment is assessed by microscopy (Eisler et al. 2001). However, the requirement for long follow-up periods (i.e. 100 days for in vivo tests in ruminants and 60 days when using mice models) makes tests cumbersome, expensive and slow, as well as susceptible to the confounding factor of re-infection after successful treatment when tests are undertaken in the field. Extrapolation of rodent data to ruminants is not necessarily an accurate reflection of treatment success in large animals and, crucially, neither $T$. vivax nor many $T$. congolense strains adapt readily to propagation in mice (Eisler et al. 2001). Nevertheless, the single-dose mouse test is currently considered the standard test to study single or multiple resistance in $T$. congolense and $T$. bruce $i$ isolates at an accelerated rate. In spite of its being non-quantitative, the test does offer a relatively rapid (60 days) means to qualitatively assess whether parasites respond to doses of drug routinely used in veterinary practice or not. Substitution of microscopy with PCR techniques, such as the ITS1 TD PCR ('Tran et al. 2014) for the detection of trypanosomes in blood, offers a mean to improve drug sensitivity studies using mouse models.

\section{In vitro methods}

Laboratory cultivation of bloodstream form $T$. brucei transformed our ability to assess sensitivity to drugs, especially in the quantities made possible by large chemical libraries and robotic screening, resulting in new lead compounds (Nare et al. 2010; De Koning et al. 2012; Diaz et al. 2014). However, as previously mentioned, field isolates of livestock trypanosome species have proven difficult to establish in culture. Initial cultivation techniques required pre-cultivation over a feeder cell layer of mammalian cells, and subsequently media without the feeder layer were developed (Baltz et al. 1985; Hirumi and Hirumi, 1994). Recently, metabolic profiling to learn exactly what $T$. brucei use from their rich culture medium has allowed development of a refined medium for growth of these parasites (Creek et al. 2013). It will be of interest to use the same methods to refine the currently limited media options for $T$. congolense and $T$. vivax.

Several in vitro assays have been developed to determine the drug sensitivity of isolates in a faster and cheaper way than in vivo tests (Kaminsky and Brun, 1993). The Alamar blue test (Räz et al. 1997) has become the gold standard. Other assays include the drug incubation infectivity test (DIIT) (Kaminsky et al. 1990) and the $\left[{ }^{3} \mathrm{H}\right]$ hypoxanthine incorporation test (Brun and Kunz, 1989), which do not require in vitro adaptation of the trypanosome strain under study, and evaluate parasite viability by their ability to respectively infect mice, or incorporate tritiated hypoxanthine, following $24 \mathrm{~h}$ exposure to drug dilutions in a culture medium. Another option for monitoring of resistance onset for $T$. congolense has been the Drug Incubation Glossina Infectivity Test (DIGIT) (Clausen et al. 1999): drug resistant and sensitive parasites are distinguished by their 
ability to infect tsetse flies following their in vitro treatment with specific doses of trypanocidal agents.

\section{Molecular methods}

Given the limitations in assessing drug sensitivity levels of veterinary trypanosomes, the development of molecular tests to determine parasites' susceptibility status would be of profound importance. For $T$. brucei group parasites it has been shown that mutations in TbAT1 and TbAQP2 genes can underlie resistance to both melaminophenyl arsenicals and to diamidines such as pentamidine (Graf et al. 2015; Munday et al. 2015a, b). The TbAT1 gene is also mutated in $T$. brucei group parasites (including $T$. $b$. evansi and T. b. equiperdum) when selected for diminazene resistance (Barrett et al. 1995; Stewart et al. 2010). Also, in T. brucei loss of the amino acid transporter TbAAT6 underlies resistance to the human African trypanocide eflornithine (Vincent et al. 2010; Schumann et al. 2011; Alsford et al. 2012). PCR-based techniques to assess status of these resistance alleles have, therefore, been possible (Kazibwe et al. 2009; Graf et al. 2013). It has also been possible to develop nongenetic tests for resistance, such as the fluorescence-based test to assess the presence or absence of the P2/TbAT1 transporter (Stewart et al. 2005).

For $T$. congolense and $T$. vivax, however, no reliable markers for drug resistance have yet emerged. As discussed above (see subsection Diminazene aceturate), the assignment of a gene named TcoAT1 as a possible marker for diminazene resistance was erroneous. The MboII-PCR-RFLP was exploited to detect the polymorphism in an ABCtype multidrug transporter putative gene related to isometamidium resistance in $T$. congolense (Delespaux et al. 2005), although this link awaits validation and has not replaced the standard in vivo assays in West Africa (Mamoudou et al. 2008). However, the possibility that the intrinsic fluorescence of isometamidium could provide a useful marker for resistance to this drug, based on observations that reduced accumulation can underlie resistance, would be useful to follow up; field application would be feasible thanks to the introduction of small but robust, battery-operated fluorescence microscopes, using long-lived light-emitting diodes as fluorescent light sources (Jones et al. 2007).

The paucity of reliable, standardized molecular and diagnostic assays for drug resistance in animal trypanosomes relates to the diversity of infecting species and the difficulties of establishing in vitro cultures for most of them. Neither the basis for drug sensitivity nor drug resistance mechanisms are necessarily shared between the main species that cause AAT ( $T$. brucei spp., $T$. vivax, T. congolense). Accordingly, it is essential that resistance mechanisms and mode of action models developed in one are properly investigated in the other species, rather than automatically assumed to apply.

\section{NEW COMPOUNDS IN THE PIPELINE}

In spite of the economic importance of the veterinary trypanosomiases (in particular of AAT) and of the spreading spectre of drug resistance, new compounds for the diseases have not emerged in many years. A similar difficulty had befallen HAT in the late 20th century, which sparked the emergence of the Drugs for Neglected Diseases initiative (DNDi) and the Consortium for Parasitic Drug Development (CPDD) (Brun et al. 2011). These organizations were founded to fill the gap left by the pharmaceutical industry, who judged the investment required to bring new drugs forward to treat diseases of the world's poorest people had no economic rationale. In the case of HAT, the clinical development of pafuramidine, an orally available prodrug of the diamidine furamidine, was halted at an advanced stage due to unforeseen toxicity issues (Paine et al. 2010). Since then, DNDi have introduced a more effective combination of two older drugs, eflornithine and nifurtimox (Priotto et al. 2009), and brought forward the nitroimidazole fexinidazole (now in phase $2 / 3$ trials as an oral treatment for second stage HAT) and also the benzoxaborole SCYX-7158 (AN5568), another orally available compound with the potential to treat second stage disease (Eperon et al. 2014). In 2011, the Global Alliance for Livestock Veterinary Medicines (GALVmed), a product development partnership supported by the UK government's Department for International Development (DFID), the Bill \& Melinda Gates Foundation and the European Commission, launched a new programme aimed at the discovery of new drugs, vaccines and diagnostics for animal trypanosomiases (https://www.galvmed. org/en/livestock-and-diseases/livestock-diseases/animalafrican-trypanosomosis/), on similar principles to the product development partnerships that have aimed to find new treatments for human diseases. A collaboration with Anacor Pharmaceuticals Inc. is hoping to develop and progress a separate benzoxaborole compound to that in human development (Jacobs et al. 2011; Steinmann et al. 2015) for the treatment and prevention of AAT. Several other compounds are entering the GALVmed portfolio, as they seek treatments that fulfil important features laid down in a target product profile (TPP), used to assess what properties compounds should have if they are to make an impact in AAT (Table 2).

Ideally, veterinary drugs, especially in resource-poor and in transhumance societies, should be of high and consistent quality, administrable in single doses sufficient to eliminate or prevent infection, be low cost with high value to the animal's owner, be active 
Table 2. Ideal TPP of a new therapeutic and prophylactic trypanocide for animal African trypanosomiasis [from (http://www.galvmed.org)].

\begin{tabular}{|c|c|c|}
\hline Attribute & Therapeutic agent & Prophylactic agent \\
\hline Active ingredient & $\begin{array}{l}\text { Novel agent (no cross-resistance to existing } \\
\text { products) }\end{array}$ & $\begin{array}{l}\text { Novel agent (no cross-resistance to existing } \\
\text { products) }\end{array}$ \\
\hline Indication for use & $\begin{array}{l}\text { T. congolense, T. vivax, T. brucei, T. evansi in- } \\
\text { cluding strains resistant to existing products }\end{array}$ & $\begin{array}{l}\text { T. congolense, T. vivax, T. brucei, T. evansi in- } \\
\text { cluding strains resistant to existing products }\end{array}$ \\
\hline Target species & $\begin{array}{l}\text { Cattle, sheep, goat \& other ruminants, camels, } \\
\text { horses, donkeys, pigs }\end{array}$ & $\begin{array}{l}\text { Cattle, sheep, goat and other ruminants, } \\
\text { camels, horses, donkeys, pigs }\end{array}$ \\
\hline $\begin{array}{l}\text { Route of } \\
\text { administration }\end{array}$ & Injectable (IM, SC), oral option for sheep & Injectable (IM, SC), oral option for sheep \\
\hline Formulation & $\begin{array}{l}\text { Pre-formulated solution (injectable), solid } \\
\text { bolus or suspension/solution drench (oral) }\end{array}$ & $\begin{array}{l}\text { Pre-formulated solution (injectable), solid } \\
\text { bolus or suspension/solution drench (oral) }\end{array}$ \\
\hline Regimen & Single dose & Single dose \\
\hline Period of protection & ot applicable & 6 months \\
\hline $\begin{array}{l}\text { Recommended time } \\
\text { of treatment }\end{array}$ & At first diagnosis & $\begin{array}{l}\text { Before (or on) introduction to infected regions } \\
\text { or at start of tsetse season. If also therapeutic: } \\
\text { use at first clinical signs of disease }\end{array}$ \\
\hline Expected efficacy & $\begin{array}{l}\text { Absence of parasitaemia and improvement of } \\
\text { clinical signs }\end{array}$ & $\begin{array}{l}\text { Absence of parasitaemia and improvement of } \\
\text { clinical signs }\end{array}$ \\
\hline Target animal safety & $\begin{array}{l}\text { No significant adverse reactions, minimal ad- } \\
\text { ministration site reaction }\end{array}$ & $\begin{array}{l}\text { No significant adverse reactions, minimal ad- } \\
\text { ministration site reaction }\end{array}$ \\
\hline Witl & $<14$ days & neat $<21-28$ days \\
\hline $\begin{array}{l}\text { Special requirements } \\
\text { for animals }\end{array}$ & $\begin{array}{l}\text { Compatible for concomitant use with common } \\
\text { treatments }\end{array}$ & $\begin{array}{l}\text { Compatible for concomitant use with common } \\
\text { treatments }\end{array}$ \\
\hline $\begin{array}{l}\text { Special requirements } \\
\text { for persons }\end{array}$ & No special precautions required & No special precautions required \\
\hline Price to user & & \\
\hline Storage requirements & Ambient temperature, $\leqslant 40{ }^{\circ} \mathrm{C} / 75 \% \mathrm{RH}$ & Ambient temperature, $\leqslant 40{ }^{\circ} \mathrm{C} / 75 \% \mathrm{RH}$ \\
\hline
\end{tabular}

IM, intramuscular; SC, subcutaneous.

on all the relevant species of trypanosomes, have good safety profiles and, for animals destined for human consumption, ideally have very short withdrawal periods. The focus should be on classes of compounds chemically different from existing trypanocides, to minimize potential cross-resistance, and on new compounds selected for slow resistance development.

As efforts to produce new trypanocides and enhanced screening against $T$. congolense and $T$. vivax as well as $T$. brucei spp. are underway, it is becoming increasingly clear that these three species of parasites respond differently to the same compounds, a fact that is likely due to the significant differences in biochemical physiology and membrane transporters of the causative parasites. Different distribution within host tissues will also influence a drug's ability to eradicate an infection. Hence, we can assume that the development of new drugs for the animal trypanosomiases will not be straightforward, will require substantial resources to make progress over a number of years, and will be necessarily linked to increased knowledge of the genetic and phenotypic differences between the three main species of African trypanosomes.

\section{CONCLUDING REMARKS}

Since the introduction of the first veterinary trypanocides more than 60 years ago, treatment of livestock trypanosomiases worldwide has seen barely any innovation, although the available drugs have progressively become less effective and the importance of these infections has not diminished. Indeed, the growing human population and the increasing demand for food (particularly meat and milk) in the tropical and subtropical countries, where these diseases are enzootic, have elevated their importance. Moreover, control of AAT is also becoming an indispensable requisite in the context of the 'One Health' approach to eliminate HAT (Simo and Rayaisse, 2015). Hence, research into new curative and chemoprophylactic drugs, with a special focus on efficacy against parasite strains resistant to current treatments, is key.

The search for new veterinary trypanocides would greatly benefit from a better understanding of the biology and the metabolism of animal trypanosomes. This knowledge will be essential to elucidate the mode of action of current trypanocides, understand the molecular factors underpinning resistance, identify new drug targets and quickly screen for new leads. This, in turn, will only be possible if improved laboratory techniques to study these parasites are developed. In particular, the definition of an in vitro culture system for the bloodstream form of T. vivax must be a high priority. At the same time, current empirically formulated culture media used for other trypanosomes should be improved, to better reflect 
physiological availability of nutrients and make their response to (experimental) drugs more predictive of the in vivo situation, including the rapid detection of resistance development in the field.

While waiting for new trypanocides to become available (which may be some years away) a correct and rational use of the few already licensed drugs is paramount to ensure continuity of their effectiveness. This requires an integrated approach that includes both vector control and appropriate livestock management. Improved, more sensitive diagnostics to promptly detect infected animals, correct treatment of these with the appropriate drug, and improvement of animal general health to help their immunological response to infection, are all important actions to be undertaken that will prolong the useful lifetime of any drug. Use of trypanotolerant breeds (in Africa) and restricting the movement of potentially infected animals (in particular those harbouring mechanically transmitted trypanosomes) are other important control measures to be implemented. The use of sanative pairs (such as diminazene and isometamidium) is essential, although ineffective on its own where multiple-drug resistant trypanosomes are present.

Constant monitoring of drug use and drug resistance appearance will be crucial for correct trypanocide use and to readily improve recommendations for first use and for back up drugs to be utilized in a certain areas when resistance has been confirmed. More efforts and resources will be needed in this field, in order to better understand the extent and the distribution of the trypanosomiases and of resistance to the veterinary trypanocides. The FAO, in collaboration with the International Atomic Energy Agency (IAEA) and the framework of the Programme Against African Trypanosomosis (PAAT) are working in this direction with the launch of the 'Atlas of tsetse and AAT', aimed at developing a geospatial database of AAT and Glossina species (Cecchi et al. 2014). For an accurate map of drug resistance occurrence, however, improved tools for its detection in the field are needed, and their development will highly depend on a more thorough understanding of the basic processes that determine resistance onset.

\section{ACKNOWLEDGEMENTS}

We are grateful to Fiona Achcar (University of Glasgow) for her assistance with the digital art.

\section{FINANCIAL SUPPORT}

F.G., L.J.M., H.D.K. and M.P.B. are funded by the BBSRC (BB/N007999/1 \& BB/N007492/1), and also, with T.G.R., by the Global Alliance for Livestock Veterinary Medicines, supported by UKAid (Department for International Development, UK Government) and Bill
\& Melinda Gates Foundation (UCE-R50A0571 and GAL/0003/0001). FG and MPB are also funded by the Wellcome Trust through a core grant to the Wellcome Trust Centre for Molecular Parasitology (104111/Z/14/ $\mathrm{Z})$. LM is a Royal Society University Research Fellow (UF140610) and the Roslin Institute is supported by a core grant from the BBSRC.

\section{REFERENCES}

Afewerk, Y., Clausen, P. H., Abebe, G., Tilahun, G. and Mehlitz, D. (2000). Multiple-drug resistant Trypanosoma congolense populations in village cattle of Metekel district, north-west Ethiopia. Acta Tropica 76, 231-238.

Agosin, M. and von Brand, T. (1954). Studies on the carbohydrate metabolism of Trypanosoma congolense. Experimental Parasitology 3, 517-524. Ahmed, S. K., Rahman, A. H., Hassan, M. A., Salih, S. E., Paone, M. and Cecchi, G. (2016). An atlas of tsetse and bovine trypanosomosis in Sudan. Parasites \& Vectors 9, 194.

Ainanshe, O. A., Jennings, F. W. and Holmes, P. H. (1992). Isolation of drug-resistant strains of Trypanosoma congolense from the lower Shabelle region of southern Somalia. Tropical Animal Health and Production 24 $65-73$.

Alirol, E., Schrumpf, D., Amici Heradi, J., Riedel, A., de Patoul, C., Quere, M. and Chappuis, F. (2013). Nifurtimox-eflornithine combination therapy for second-stage gambiense human African trypanosomiasis: medecins Sans Frontieres experience in the Democratic Republic of the Congo. Clinical Infectious Diseases 56, 195-203.

Alkhaldi, A. A., Martinek, J., Panicucci, B., Dardonville, C., Zikova, A. and de Koning, H. P. (2016). Trypanocidal action of bisphosphonium salts through a mitochondrial target in bloodstream form Trypanosoma brucei. International Fournal for Parasitology: Drugs and Drug Resistance 6, 23-34.

Alsford, S., Eckert, S., Baker, N., Glover, L., Sanchez-Flores, A., Leung, K.F., Turner, D. J., Field, M. C., Berriman, M. and Horn, D. (2012). High-throughput decoding of antitrypanosomal drug efficacy and resistance. Nature 482, 232-236.

Apted, F. I. (1970). Treatment of human trypanosomiasis. In The African Trypanosomiases (ed. Mulligan, H. W.), pp. 684-710. George Allen and Unwin Ltd., London, UK.

Auty, H., Mundy, A., Fyumagwa, R. D., Picozzi, K., Welburn, S. and Hoare, R. (2008). Health management of horses under high challenge from trypanosomes: a case study from Serengeti, Tanzania. Veterinary Parasitology 154, 233-241.

Auty, H., Anderson, N. E., Picozzi, K., Lembo, T., Mubanga, J., Hoare, R., Fyumagwa, R. D., Mable, B., Hamill, L., Cleaveland, S. and Welburn, S.C. (2012). Trypanosome diversity in wildlife species from the serengeti and Luangwa Valley ecosystems. PLoS Neglected Tropical Diseases 6, e1828.

Auty, H., Torr, S. J., Michoel, T., Jayaraman, S. and Morrison, L. J. (2015). Cattle trypanosomosis: the diversity of trypanosomes and implications for disease epidemiology and control. Revue Scientifique et Technique de l'OIE 34, 587-598.

Baker, N., Glover, L., Munday, J. C., Aguinaga, A. D., Barrett, M. P., de Koning, H. P. and Horn, D. (2012). Aquaglyceroporin 2 controls susceptibility to melarsoprol and pentamidine in African trypanosomes. Proceedings of the National Academy of Sciences of the United States of America 109, 10996-11001.

Baker, N., de Koning, H. P., Maser, P. and Horn, D. (2013). Drug resistance in African trypanosomiasis: the melarsoprol and pentamidine story. Trends in Parasitology 29, 110-118.

Baker, N., Hamilton, G., Wilkes, J. M., Hutchinson, S., Barrett, M. P. and Horn, D. (2015). Vacuolar ATPase depletion affects mitochondrial ATPase function, kinetoplast dependency, and drug sensitivity in trypanosomes. Proceedings of the National Academy of Sciences of the United States of America 112, 9112-9117.

Baltz, T., Baltz, D., Giroud, C. and Crockett, J. (1985). Cultivation in a semi-defined medium of animal infective forms of Trypanosoma brucei, T. equiperdum, T. evansi, T. rhodesiense and T. gambiense. EMBO fournal 4, 1273-1277.

Banks, K. L. (1979). In vitro binding of Trypanosoma congolense to erythrocytes. Fournal of Protozoology 26, 103-108.

Banks, K. L. (1980). Injury induced by Trypanosoma congolense adhesion to cell membranes. Fournal of Parasitology 66, 34-37.

Barrett, M. P. and Fairlamb, A. H. (1999). The biochemical basis of arsenical-diamidine crossresistance in African trypanosomes. Parasitology Today 15, 136-140. 
Barrett, M.P., Zhang, Z. Q., Denise, H., Giroud, C. and Baltz, T. (1995). A diamidine-resistant Trypanosoma equiperdum clone contains a P2 purine transporter with reduced substrate affinity. Molecular and Biochemical Parasitology 73, 223-229.

Barrett, M. P., Burchmore, R. J., Stich, A., Lazzari, J. O., Frasch, A. C., Cazzulo, J. J. and Krishna, S. (2003). The trypanosomiases. Lancet 362, 1469-1480.

Barrett, M. P., Boykin, D. W., Brun, R. and Tidwell, R. R. (2007). Human African trypanosomiasis: pharmacological re-engagement with a neglected disease. British Fournal of Pharmacology 152, 1155-1171

Batista, J.S., Riet-Correa, F., Teixeira, M. M., Madruga, C. R., Simoes, S. D. and Maia, T. F. (2007). Trypanosomiasis by Trypanosoma vivax in cattle in the Brazilian semiarid: description of an outbreak and lesions in the nervous system. Veterinary Parasitology 143, 174-181.

Batista, J. S., Oliveira, A.F., Rodrigues, C. M., Damasceno, C. A., Oliveira, I. R., Alves, H. M., Paiva, E. S., Brito, P. D., Medeiros, J. M., Rodrigues, A. C. and Teixeira, M. M. (2009). Infection by Trypanosoma vivax in goats and sheep in the Brazilian semiarid region: from acute disease outbreak to chronic cryptic infection. Veterinary Parasitology 165, 131-135.

Batista, J. S., Rodrigues, C. M., Olinda, R. G., Silva, T. M., Vale, R. G., Camara, A. C., Reboucas, R. E., Bezerra, F. S., Garcia, H. A. and Teixeira, M.M. (2012). Highly debilitating natural Trypanosoma vivax infections in Brazilian calves: epidemiology, pathology, and probable transplacental transmission. Parasitology Research 110, 73-80.

Bengaly, Z., Sidibe, I., Boly, H., Sawadogo, L. and Desquesnes, M. $(2002 a)$. Comparative pathogenicity of three genetically distinct Trypanosoma congolense-types in inbred Balb/c mice. Veterinary Parasitology 105, 111-118.

Bengaly, Z., Sidibe, I., Ganaba, R., Desquesnes, M., Boly, H. and Sawadogo, L. (2002b). Comparative pathogenicity of three genetically distinct types of Trypanosoma congolense in cattle: clinical observations and haematological changes. Veterinary Parasitology 108, 1-19.

Bennett, S. C. J. (1930). Camel trypanosomiasis in the Sudan. In Proceedings of the 1929 Pan African Veterinary Conference, Pretoria, South Africa, pp. 10-15.

Bennett, S. C. J. (1936). The treatment of equine Trypanosoma congolense infections with Surfen C (Bayer). Fournal of Comparative Pathology and Therapeutics 49, 151-159.

Berger, B. J. and Fairlamb, A.H. (1994). Properties of melarsamine hydrochloride (Cymelarsan) in aqueous solution. Antimicrobial Agents and Chemotherapy 38, 1298-1302.

Berlin, D., Nasereddin, A., Azmi, K., Ereqat, S., Abdeen, Z. and Baneth, G. (2010). Longitudinal study of an outbreak of Trypanosoma evansi infection in equids and dromedary camels in Israel. Veterinary Parasitology 174, 317-322.

Berriman, M., Ghedin, E., Hertz-Fowler, C., Blandin, G., Renauld, H., Bartholomeu, D. C., Lennard, N. J., Caler, E., Hamlin, N. E., Haas, B., Bohme, U., Hannick, L., Aslett, M. A., Shallom, J., Marcello, L., Hou, L., Wickstead, B., Alsmark, U.C., Arrowsmith, C., Atkin, R. J., Barron, A. J., Bringaud, F., Brooks, K., Carrington, M., Cherevach, I., Chillingworth, T. J., Churcher, C., Clark, L. N., Corton, C. H., Cronin, A. et al. (2005). The genome of the African trypanosome Trypanosoma brucei. Science 309, 416-422.

Biryomumaisho, S., Rwakishaya, E. K., Melville, S. E., Cailleau, A. and Lubega, G. W. (2013). Livestock trypanosomosis in Uganda: parasite heterogeneity and anaemia status of naturally infected cattle, goats and pigs. Parasitology Research 112, 1443-1450.

Biteau, N., Asencio, C., Izotte, J., Rousseau, B., Fevre, M., Pillay, D. and Baltz, T. (2016). Trypanosoma brucei gambiense infections in mice lead to tropism to the reproductive organs, and horizontal and vertical transmission. PLoS Neglected Tropical Diseases 10, e0004350.

Blum, J., Nkunku, S. and Burri, C. (2001). Clinical description of encephalopathic syndromes and risk factors for their occurrence and outcome during melarsoprol treatment of human African trypanosomiasis. Tropical Medicine \& International Health 6, 390-400.

Boibessot, I., Turner, C. M., Watson, D. G., Goldie, E., Connel, G., McIntosh, A., Grant, M. H. and Skellern, G. G. (2002). Metabolism and distribution of phenanthridine trypanocides in Trypanosoma brucei. Acta Tropica 84, 219-228.

Boid, R., Jones, T. W. and Payne, R. C. (1989). Malic enzyme type VII isoenzyme as an indicator of suramin resistance in Trypanosoma evansi. Experimental Parasitology 69, 317-323.

Brun, R. and Kunz, C. (1989). In vitro drug sensitivity test for Trypanosoma brucei subgroup bloodstream trypomastigotes. Acta Tropica 46, 361-368.

Brun, R. and Lun, Z. R. (1994). Drug sensitivity of Chinese Trypanosoma evansi and Trypanosoma equiperdum isolates. Veterinary Parasitology 52, 37-46.
Brun, R. and Moloo, S. K. (1982). In vitro cultivation of animal-infective forms of a West African Trypanosoma vivax stock. Acta Tropica 39, 135-141. Brun, R., Hecker, H. and Lun, Z. R. (1998). Trypanosoma evansi and T. equiperdum: distribution, biology, treatment and phylogenetic relationship (a review). Veterinary Parasitology 79, 95-107.

Brun, R., Don, R., Jacobs, R. T., Wang, M. Z. and Barrett, M. P. (2011). Development of novel drugs for human African trypanosomiasis. Future Microbiology 6, 677-691.

Cadioli, F.A., Barnabé, P.A., Machado, R.Z., Teixeira, M.C., André, M. R., Sampaio, P. H., Fidélis Junior, O. L., Teixeira, M. M. and Marques, L. C. (2012). First report of Trypanosoma vivax outbreak in dairy cattle in Sao Paulo state, Brazil. Revista Brasileira de Parasitologia Veterinaria 21, 118-124.

Carnes, J., Anupama, A., Balmer, O., Jackson, A., Lewis, M., Brown, R., Cestari, I., Desquesnes, M., Gendrin, C., HertzFowler, C., Imamura, H., Ivens, A., Koreny, L., Lai, D. H., MacLeod, A., McDermott, S. M., Merritt, C., Monnerat, S., Moon, W., Myler, P., Phan, I., Ramasamy, G., Sivam, D., Lun, Z. R., Lukes, J., Stuart, K. and Schnaufer, A. (2015). Genome and phylogenetic analyses of Trypanosoma evansi reveal extensive similarity to $T$. brucei and multiple independent origins for dyskinetoplasty. PLoS Neglected Tropical Diseases 9, e3404.

Carter, N.S. and Fairlamb, A.H. (1993). Arsenical-resistant trypanosomes lack an unusual adenosine transporter. Nature 361, 173-176.

Carter, N. S., Berger, B. J. and Fairlamb, A. H. (1995). Uptake of diamidine drugs by the P2 nucleoside transporter in melarsen-sensitive and -resistant Trypanosoma brucei brucei. Fournal of Biological Chemistry 270, 28153-28157

Cecchi, G. and Mattioli, R. C. (2009). Geospacial Datasets and Analyses for an Environmental Approach to African Trypanosomiasis. PAAT Technical and Scientific Series No. 9. Food and Agriculture Organisation of the United Nations (FAO), Rome, Italy.

Cecchi, G., Paone, M., Feldmann, U., Vreysen, M. J., Diall, O. and Mattioli, R. C. (2014). Assembling a geospatial database of tsetse-transmitted animal trypanosomosis for Africa. Parasites \& Vectors 7, 39

Chitambo, H. and Arakawa, A. (1992a). Trypanosoma congolense: manifestation of resistance to Berenil and Samorin in cloned trypanosomes isolated from Zambian cattle. Zentralblatt fur Bakteriologie 277, 371-381. Chitambo, H. and Arakawa, A. (1992b). Trypanosoma congolense: the in vitro akinetoplastic induction sensitivity assay. Parasitology Research 78, 136-141.

Chitanga, S., Marcotty, T., Namangala, B., Van den Bossche, P., Van Den Abbeele, J. and Delespaux, V. (2011). High prevalence of drug resistance in animal trypanosomes without a history of drug exposure. PLoS Neglected Tropical Diseases 5, e1454

Claes, F., Buscher, P., Touratier, L. and Goddeeris, B. M. (2005) Trypanosoma equiperdum: master of disguise or historical mistake? Trends in Parasitology 21, 316-321.

Clausen, P. H., Sidibe, I., Kabore, I. and Bauer, B. (1992). Development of multiple drug resistance of Trypanosoma congolense in Zebu cattle under high natural tsetse fly challenge in the pastoral zone of Samorogouan, Burkina Faso. Acta Tropica 51, 229-236.

Clausen, P. H., Leendertz, F.H., Blankenburg, A., Tietjen, U., Mehlitz, D., Sidibe, I. and Bauer, B. (1999). A drug incubation glossina infectivity test (DIGIT) to assess the susceptibility of Trypanosoma congolense bloodstream forms to trypanocidal drugs (Xenodiagnosis). Acta Tropica 72, 111-117.

Cnops, J., Magez, S. and De Trez, C. (2015). Escape mechanisms of African trypanosomes: why trypanosomosis is keeping us awake. Parasitology 142, 417-427.

Codjia, V., Mulatu, W., Majiwa, P. A., Leak, S. G., Rowlands, G. J., Authie, E., d'Ieteren, G. D. and Peregrine, A.S. (1993) Epidemiology of bovine trypanosomiasis in the Ghibe valley, southwest Ethiopia. 3. Occurrence of populations of Trypanosoma congolense resistant to diminazene, isometamidium and homidium. Acta Tropica 53, 151-163. Coles, J. A., Myburgh, E., Ritchie, R., Hamilton, A., Rodgers, J., Mottram, J. C., Barrett, M.P. and Brewer, J. M. (2015). Intravital imaging of a massive lymphocyte response in the cortical dura of mice after peripheral infection by trypanosomes. PLoS Neglected Tropical Diseases 9, e0003714.

Connor, R. J. (1992). The diagnosis, treatment and prevention of animal trypanosomiasis under field conditions. In Programme for the Control of African Animal Trypanosomiasis and Related Development: Ecological and Technical Aspects. FAO Animal Production and Health Paper No. 100. Food and Agriculture Organisation of the United Nations (FAO), Rome, Italy

Cortez, A. P., Ventura, R. M., Rodrigues, A. C., Batista, J. S., Paiva, F., Anez, N., Machado, R. Z., Gibson, W. C. and Teixeira, M. M. (2006) 
The taxonomic and phylogenetic relationships of Trypanosoma vivax from South America and Africa. Parasitology 133, 159-169.

Coustou, V., Guegan, F., Plazolles, N. and Baltz, T. (2010). Complete in vitro life cycle of Trypanosoma congolense: development of genetic tools. PLoS Neglected Tropical Diseases 4, e618.

Cox, B. A., Yielding, L. W. and Yielding, K. L. (1984). Subcellular localization of photoreactive ethidium analogs in Trypanosoma brucei by fluorescence microscopy. Fournal of Parasitology 70, 694-702.

Creek, D. J., Nijagal, B., Kim, D. H., Rojas, F., Matthews, K. R. and Barrett, M. P. (2013). Metabolomics guides rational development of a simplified cell culture medium for drug screening against Trypanosoma brucei. Antimicrobial Agents and Chemotherapy 57, 2768-2779.

Creek, D. J., Mazet, M., Achcar, F., Anderson, J., Kim, D. H., Kamour, R., Morand, P., Millerioux, Y., Biran, M., Kerkhoven, E. J., Chokkathukalam, A., Weidt, S. K., Burgess, K. E., Breitling, R., Watson, D. G., Bringaud, F. and Barrett, M. P. (2015). Probing the metabolic network in bloodstream-form Trypanosoma brucei using untargeted metabolomics with stable isotope labelled glucose. PLoS Pathogens 11, e1004689.

Curd, F. H. and Davey, D. G. (1950). Antrycide - a new trypanocidal drug. British Fournal of Pharmacology 5, 25-32.

D’Archivio, S., Medina, M., Cosson, A., Chamond, N., Rotureau, B. Minoprio, P. and Goyard, S. (2011). Genetic engineering of Trypanosoma (Dutonella) vivax and in vitro differentiation under axenic conditions. PLoS Neglected Tropical Diseases 5, e1461.

D’Archivio, S., Cosson, A., Medina, M., Lang, T., Minoprio, P. and Goyard, S. (2013). Non-invasive in vivo study of the Trypanosoma vivax infectious process consolidates the brain commitment in late infections. PLoS Neglected Tropical Diseases 7, e1976.

Dagnachew, S., Terefe, G., Abebe, G., Barry, D., McCulloch, R. and Goddeeris, B. (2015). In vivo experimental drug resistance study in Trypanosoma vivax isolates from tsetse infested and non-tsetse infested areas of Northwest Ethiopia. Acta Tropica 146, 95-100.

Dargantes, A. P., Mercado, R. T., Dobson, R. J. and Reid, S. A. (2009). Estimating the impact of Trypanosoma evansi infection (surra) on buffalo population dynamics in southern Philippines using data from cross-sectional surveys. International fournal for Parasitology 39, 1109-1114.

Da Silva, A. S., Garcia Perez, H. A., Costa, M. M., Franca, R. T., De Gasperi, D., Zanette, R. A., Amado, J. A., Lopes, S. T., Teixeira, M. M. and Monteiro, S. G. (2011). Horses naturally infected by Trypanosoma vivax in southern Brazil. Parasitology Research 108, 23-30.

De Koning, H.P. (2001a). Transporters in African trypanosomes: role in drug action and resistance. International Fournal for Parasitology 31, $512-522$.

De Koning, H.P. (2001b). Uptake of pentamidine in Trypanosoma brucei bruce $i$ is mediated by three distinct transporters: implications for cross-resistance with arsenicals. Molecular Pharmacology 59, 586-592.

De Koning, H. P. (2008). Ever-increasing complexities of diamidine and arsenical crossresistance in African trypanosomes. Trends in Parasitology 24, 345-349.

De Koning, H. P. and Jarvis, S. M. (1999). Adenosine transporters in bloodstream forms of Trypanosoma brucei brucei: substrate recognition motifs and affinity for trypanocidal drugs. Molecular Pharmacology 56, $1162-1170$

De Koning, H.P., Anderson, L.F., Stewart, M., Burchmore, R. J., Wallace, L. J. and Barrett, M. P. (2004). The trypanocide diminazene aceturate is accumulated predominantly through the TbAT1 purine transporter: additional insights on diamidine resistance in African trypanosomes. Antimicrobial Agents and Chemotherapy 48, 1515-1519.

De Koning, H. P., Gould, M. K., Sterk, G. J., Tenor, H., Kunz, S. Luginbuehl, E. and Seebeck, T. (2012). Pharmacological validation of Trypanosoma brucei phosphodiesterases as novel drug targets. Fournal of Infectious Diseases 206, 229-237.

Dean, S., Gould, M. K., Dewar, C.E. and Schnaufer, A. C. (2013) Single point mutations in ATP synthase compensate for mitochondrial genome loss in trypanosomes. Proceedings of the National Academy of Sciences of the United States of America 110, 14741-14746.

Defontis, M., Richartz, J., Engelmann, N., Bauer, C., Schwierk, V. M., Buscher, P. and Moritz, A. (2012). Canine Trypanosoma evansi infection introduced into Germany. Veterinary Clinical Pathology 41, 369-374 Delespaux, V. and de Koning, H. P. (2007). Drugs and drug resistance in African trypanosomiasis. Drug Resistance Updates 10, 30-50.

Delespaux, V., Geysen, D., Majiwa, P. A. and Geerts, S. (2005). Identification of a genetic marker for isometamidium chloride resistance in Trypanosoma congolense. International fournal for Parasitology 35, 235-243.

Delespaux, V., Chitanga, S., Geysen, D., Goethals, A., Van den Bossche, P. and Geerts, S. (2006). SSCP analysis of the P2 purine transporter TcoAT1 gene of Trypanosoma congolense leads to a simple PCR-RFLP test allowing the rapid identification of diminazene resistant stocks. Acta Tropica 100, 96-102.

Delespaux, V., Dinka, H., Masumu, J., Van den Bossche, P. and Geerts, S. (2008a). Five-fold increase in Trypanosoma congolense isolates resistant to diminazene aceturate over a seven-year period in Eastern Zambia. Drug Resistance Updates 11, 205-209.

Delespaux, V., Geysen, D., Van den Bossche, P. and Geerts, S. (2008b). Molecular tools for the rapid detection of drug resistance in animal trypanosomes. Trends in Parasitology 24, 236-242.

Desowitz, R.S. (1956). Observations on the metabolism of Trypanosoma vivax. Experimental Parasitology 5, 250-259.

Desowitz, R. S. (1957). Suramin complexes. II. Prophylactic activity against Trypanosoma vivax in cattle. Annals of Tropical Medicine and Parasitology 51, 457-463.

Desquesnes, M. and Dia, M. L. (2003). Mechanical transmission of Trypanosoma congolense in cattle by the African tabanid Atylotus agrestis. Experimental Parasitology 105, 226-231.

Desquesnes, M. and Davila, A. M. (2002). Applications of PCR-based tools for detection and identification of animal trypanosomes: a review and perspectives. Veterinary Parasitology 109, 213-231.

Desquesnes, M., de La Rocque, S. and Peregrine, A. S. (1995). French Guyanan stock of Trypanosoma vivax resistant to diminazene aceturate but sensitive to isometamidium chloride. Acta Tropica 60, 133-136.

Desquesnes, M., Bossard, G., Patrel, D., Herder, S., Patout, O., Lepetitcolin, E., Thevenon, S., Berthier, D., Pavlovic, D., Brugidou, R., Jacquiet, P., Schelcher, F., Faye, B., Touratier, L. and Cuny, G. (2008). First outbreak of Trypanosoma evansi in camels in metropolitan France. Veterinary Record 162, 750-752.

Desquesnes, M., Biteau-Coroller, F., Bouyer, J., Dia, M. L. and Foil, L. (2009). Development of a mathematical model for mechanical transmission of trypanosomes and other pathogens of cattle transmitted by tabanids. International fournal for Parasitology 39, 333-346.

Desquesnes, M., Kamyingkird, K., Vergne, T., Sarataphan, N., Pranee, R. and Jittapalapong, S. (2011). An evaluation of melarsomine hydrochloride efficacy for parasitological cure in experimental infection of dairy cattle with Trypanosoma evansi in Thailand. Parasitology 138, 1134-1142.

Desquesnes, M., Dargantes, A., Lai, D. H., Lun, Z. R., Holzmuller, P. and Jittapalapong, S. (2013a). Trypanosoma evansi and surra: a review and perspectives on transmission, epidemiology and control, impact, and zoonotic aspects. BioMed Research International 2013, 321237.

Desquesnes, M., Holzmuller, P., Lai, D. H., Dargantes, A., Lun, Z. R and Jittaplapong, S. (2013b). Trypanosoma evansi and surra: a review and perspectives on origin, history, distribution, taxonomy, morphology, hosts, and pathogenic effects. BioMed Research International 2013, 194176.

Diaz, R., Luengo-Arratta, S. A., Seixas, J. D., Amata, E., Devine, W., Cordon-Obras, C., Rojas-Barros, D. I., Jimenez, E., Ortega, F., Crouch, S., Colmenarejo, G., Fiandor, J. M., Martin, J. J., Berlanga, M., Gonzalez, S., Manzano, P., Navarro, M. and Pollastri, M. P. (2014). Identification and characterization of hundreds of potent and selective inhibitors of Trypanosoma brucei growth from a kinase-targeted library screening campaign. PLoS Neglected Tropical Diseases 8, e3253

Dobson, R. J., Dargantes, A. P., Mercado, R. T. and Reid, S. A. (2009) Models for Trypanosoma evansi (surra), its control and economic impact on small-hold livestock owners in the Philippines. International fournal for Parasitology 39, 1115-1123.

Dolan, R. B., Okech, G., Alushula, H., Mutugi, M., Stevenson, P., Sayer, P. D. and Njogu, A. R. (1990). Homidium bromide as a chemoprophylactic for cattle trypanosomiasis in Kenya. Acta Tropica 47, 137-144

Doua, F., Miezan, T. W., Sanon Singaro, J. R., Boa Yapo, F. and Baltz, T. (1996). The efficacy of pentamidine in the treatment of earlylate stage Trypanosoma brucei gambiense trypanosomiasis. The American Journal of Tropical Medicine and Hygiene 55, 586-588.

Dougherty, G. and Waring, M. J. (1982). The interaction between prothidium dibromide and DNA at the molecular level. Biophysical Chemistry 15, 27-40.

Dowler, M. E., Schillinger, D. and Connor, R. J. (1989). Notes on the routine intravenous use of isometamidium in the control of bovine trypanosomiasis on the Kenya coast. Tropical Animal Health and Production 21, 4-10.

Eisler, M. C. (1996). Pharmacokinetics of the chemoprophylactic and chemotherapeutic trypanocidal drug isometamidium chloride (Samorin) in cattle. Drug Metabolism and Disposition 24, 1355-1361.

Eisler, M. C., Arowolo, R. O., Gault, E. A., Moloo, S. K., Holmes, P. H. and Peregrine, A. S. (1994). Isometamidium concentrations in the 
sera of Boran cattle: correlation with prophylaxis against tsetse-transmitted Trypanosoma congolense. Acta Tropica 56, 39-50.

Eisler, M. C., McDermott, J. J., Mdachi, R., Murilla, G. A., Sinyangwe, L., Mubanga, J., Machila, N., Mbwambo, H., Coleman, P. G., Clausen, P. H., Bauer, B., Sidibé, I., Geerts, S., Holmes, P. H. and Peregrine, A. S. (2000). Rapid method for the assessment of trypanocidal drug resistance in the field. In Proceedings of the 9th Symposium of the International Society for Veterinary Epidemiology and Economics, Nairobi, Kenya, paper 353 1-3.

Eisler, M. C., Brandt, J., Bauer, B., Clausen, P.H., Delespaux, V., Holmes, P. H., Ilemobade, A., Machila, N., Mbwambo, H., McDermott, J., Mehlitz, D., Murilla, G., Ndung'u, J. M., Peregrine, A. S., Sidibe, I., Sinyangwe, L. and Geerts, S. (2001). Standardised tests in mice and cattle for the detection of drug resistance in tsetse-transmitted trypanosomes of African domestic cattle. Veterinary Parasitology 97, 171-182.

El Banna, H. A., Abo el-Sooud, K. and Soliman, G. A. (1999). Comparative pharmacokinetics of diminazene in lactating goats and sheep. Zentralblatt für Veterinärmedizin. Reihe A 46, 49-57.

El Rayah, I. E., Kaminsky, R., Schmid, C. and El Malik, K. H. (1999). Drug resistance in Sudanese Trypanosoma evansi. Veterinary Parasitology 80, 281-287.

Eperon, G., Balasegaram, M., Potet, J., Mowbray, C., Valverde, O. and Chappuis, F. (2014). Treatment options for second-stage gambiense human African trypanosomiasis. Expert Review of Anti-Infective Therapy 12, 1407-1417

Eze, A. A., Gould, M. K., Munday, J. C., Tagoe, D., Stelmanis, V., Schnaufer, A. C. and de Koning, H. P. (2016). Loss of mitochondrial membrane potential is a late adaptation of Trypanosoma brucei brucei to isometamidium preceded by mutations in the $\gamma$ subunit of the $F_{1} F_{0}$-ATPase. PLoS Neglected Tropical Diseases 10, e0004791.

Faccio, L., Da Silva, A.S., Gressler, L. T., Tonin, A. A., Lazzarotto, C. R., Miletti, L.C. and Monteiro, S. G. (2013). Susceptibility of Brazilian isolates of Trypanosoma evansi to suramin sodium: test in experimentally infected mice. Experimental Parasitology 134, 309-312.

Fairlamb, A. H. (2003). Chemotherapy of human African trypanosomiasis: current and future prospects. Trends in Parasitology 19, 488-494.

Fairlamb, A. H. and Bowman, I. B. (1980). Uptake of the trypanocidal drug suramin by bloodstream forms of Trypanosoma brucei and its effect on respiration and growth rate in vivo. Molecular and Biochemical Parasitology 1, 315-333.

FAO (1990). Residues of Some Veterinary Drugs in Animals and Foods. FAO Food and Nutrition paper No. 41/2. Food and Agriculture Organization of the United Nations (FAO), Rome, Italy

Gardiner, P. R. (1989). Recent studies of the biology of Trypanosoma vivax. Advances in Parasitology 28, 229-317.

Geerts, S. and Holmes, P.H. (1998). Drug Management and Parasite Resistance in Bovine Trypanosomiasis in Africa. PAAT Technical and Scientific Series No. 1. Food and Agriculture Organisation of the United Nations (FAO), Rome, Italy.

Geerts, S., Brandt, J. and De Deken, R. (1999). Laboratory and field evaluation of biodegradable polyesters for sustained release of isometamidium and ethidium - Minireview. Memórias do Instituto Oszualdo Cruz 94, 211-214.

Geerts, S., Holmes, P. H., Eisler, M. C. and Diall, O. (2001). African bovine trypanosomiasis: the problem of drug resistance. Trends in Parasitology 17, 25-28.

Gibson, W. (2012). The origins of the trypanosome genome strains Trypanosoma brucei brucei TREU 927, T. b. gambiense DAL 972, T. vivax Y486 and T. congolense IL3000. Parasites \& Vectors 5, 71

Gill, B. S. (1971). Drug-resistance in Trypanosoma evansi. Tropical Animal Health and Production 3, 195-198.

Gould, M. K. and Schnaufer, A. (2014). Independence from kinetoplast DNA maintenance and expression is associated with multidrug resistance in Trypanosoma brucei in vitro. Antimicrobial Agents and Chemotherapy 58, 2925-2928.

Grab, D. J. and Kennedy, P. G. (2008). Traversal of human and animal trypanosomes across the blood-brain barrier. Fournal of Neurovirology $\mathbf{1 4}$, 344-351

Grace, D., Randolph, T., Affognon, H., Dramane, D., Diall, O. and Clausen, P. H. (2009). Characterisation and validation of farmers' knowledge and practice of cattle trypanosomosis management in the cotton zone of West Africa. Acta Tropica 111, 137-143.

Graf, F. E., Ludin, P., Wenzler, T., Kaiser, M., Brun, R., Pyana, P. P., Buscher, P., de Koning, H.P., Horn, D. and Maser, P. (2013). Aquaporin 2 mutations in Trypanosoma brucei gambiense field isolates correlate with decreased susceptibility to pentamidine and melarsoprol. PLoS Neglected Tropical Diseases 7, e2475.
Graf, F. E., Baker, N., Munday, J. C., de Koning, H. P., Horn, D. and Maser, P. (2015). Chimerization at the AQP2-AQP3 locus is the genetic basis of melarsoprol-pentamidine cross-resistance in clinical Trypanosoma brucei gambiense isolates. International Fournal for Parasitology: Drugs and Drug Resistance 5, 65-68.

Gray, M. A., Kimarua, R. W., Peregrine, A. S. and Stevenson, P. (1993). Drug sensitivity screening in vitro of populations of Trypanosoma congolense originating from cattle and tsetse flies at Nguruman, Kenya. Acta Tropica 55, 1-9.

Griffin, L. (1983). Congenital transmission of Trypanosoma congolense in mice. Fournal of Comparative Pathology 93, 489-492.

Gu, Y., Gettinby, G., McKendrick, I., Murry, M., Peregrine, A.S. and Revie, C. (1999). Development of a decision support system for trypanocidal drug control of bovine trypanosomosis in Africa. Veterinary Parasitology 87, 9-23.

Gutierrez, C., Corbera, J. A., Bayou, K. and van Gool, F. (2008). Use of cymelarsan in goats chronically infected with Trypanosoma evansi. Annals of the New York Academy of Sciences 1149, 331-333.

Gutierrez, C., Desquesnes, M., Touratier, L. and Buscher, P. (2010). Trypanosoma evansi: recent outbreaks in Europe. Veterinary Parasitology 174, 26-29.

Gutteridge, W. E. (1985). Existing chemotherapy and its limitations. British Medical Bulletin 41, 162-168.

Haag, J., O'hUigin, C. and Overath, P. (1998). The molecular phylogeny of trypanosomes: evidence for an early divergence of the Salivaria Molecular and Biochemical Parasitology 91, 37-49.

Hagos, A., Goddeeris, B. M., Yilkal, K., Alemu, T., Fikru, R., Yacob, H. T., Feseha, G. and Claes, F. (2010). Efficacy of Cymelarsan and Diminasan against Trypanosoma equiperdum infections in mice and horses. Veterinary Parasitology 171, 200-206.

Hanau, S., Rippa, M., Bertelli, M., Dallocchio, F. and Barrett, M. P. (1996). 6-Phosphogluconate dehydrogenase from Trypanosoma brucei. Kinetic analysis and inhibition by trypanocidal drugs. European fournal of Biochemistry 240, 592-599.

Haridy, F. M., El-Metwally, M. T., Khalil, H. H. and Morsy, T. A. (2011). Trypanosoma evansi in dromedary camel: with a case report of zoonosis in greater Cairo, Egypt. Fournal of the Egyptian Society of Parasitology 41, 65-76.

Hawking, F. (1963). Chemotherapy of trypanosomiasis. In Experimental Chemotherapy, Vol. 1 (ed. Schnitzer, R. J. and Hawking, F.), pp. 129 256. Academic Press, New York and London.

Hemphill, A., Frame, I. and Ross, C. A. (1994). The interaction of Trypanosoma congolense with endothelial cells. Parasitology 109 (Pt 5), 631-641.

Hettlich, B. F., Ryan, K., Bergman, R. L., Marks, S. L., Lewis, B. C., Bahr, A., Coates, J. R., Mansell, J. and Barton, C. L. (2003). Neurologic complications after melarsomine dihydrochloride treatment for Dirofilaria immitis in three dogs. Fournal of the American Veterinary Medical Association 223, 1456-1461, 1434.

Hide, G. and Tait, A. (2004). Genetics and molecular epidemiology of trypanosomes. In The Trypanosomiases (ed. Maudlin, I., Holmes, P. H. and Miles, M. A.), pp. 77-93. CAB International, Wallingford, UK.

Hirumi, H. and Hirumi, K. (1994). Axenic culture of African trypanosome bloodstream forms. Parasitology Today 10, 80-84.

Holmes, P. (2013). Tsetse-transmitted trypanosomes - their biology, disease impact and control. Fournal of Invertebrate Pathology 112 (Suppl.), S11-S14.

Holmes, P. H., Eisler, M. C. and Geerts, S. (2004). Current chemotherapy of animal trypanosomiasis. In The Trypanosomiases (ed. Maudlin, I., Holmes, P. H. and Miles, M. A.), pp. 431-444. CAB International, Wallingford, UK.

Horn, D. (2014). Antigenic variation in African trypanosomes. Molecular and Biochemical Parasitology 195, 123-129.

Howie, S., Guy, M., Fleming, L., Bailey, W., Noyes, H., Faye, J. A., Pepin, J., Greenwood, B., Whittle, H., Molyneux, D. and Corrah, T. (2006). A Gambian infant with fever and an unexpected blood film. PLoS Medicine 3, e355.

Ibrahim, H.M., Al-Salabi, M. I., El Sabbagh, N., Quashie, N. B., Alkhaldi, A. A., Escale, R., Smith, T. K., Vial, H. J. and de Koning, H. P. (2011). Symmetrical choline-derived dications display strong anti-kinetoplastid activity. Fournal of Antimicrobial Chemotherapy 66, 111-125.

Igoli, J. O., Blackburn, G., Gray, A. I., Sutcliffe, O. B., Watson, D. G., Euerby, M. R. and Skellern, G. G. (2015). Chromatographic and spectroscopic analysis of the components present in the phenanthridinium trypanocidal agent isometamidium. Analytical and Bioanalytical Chemistry 407, 1171-1180. Inoue, N., Otsu, K., Ferraro, D. M. and Donelson, J. E. (2002). Tetracycline-regulated RNA interference in Trypanosoma congolense. Molecular and Biochemical Parasitology 120, 309-313. 
Jackson, A.P., Berry, A., Aslett, M., Allison, H. C., Burton, P., Vavrova-Anderson, J., Brown, R., Browne, H., Corton, N., Hauser, H., Gamble, J., Gilderthorp, R., Marcello, L., McQuillan, J., Otto, T.D., Quail, M. A., Sanders, M. J., van Tonder, A., Ginger, M. L., Field, M. C., Barry, J. D., HertzFowler, C. and Berriman, M. (2012). Antigenic diversity is generated by distinct evolutionary mechanisms in African trypanosome species. Proceedings of the National Academy of Sciences of the United States of America 109, 3416-3421.

Jacobs, R. T., Nare, B., Wring, S. A., Orr, M. D., Chen, D., Sligar, J. M., Jenks, M.X., Noe, R. A., Bowling, T.S., Mercer, L.T., Rewerts, C., Gaukel, E., Owens, J., Parham, R., Randolph, R., Beaudet, B., Bacchi, C. J., Yarlett, N., Plattner, J. J., Freund, Y., Ding, C., Akama, T., Zhang, Y.K., Brun, R., Kaiser, M., Scandale, I. and Don, R. (2011). SCYX-7158, an orally-active benzoxaborole for the treatment of stage 2 human African trypanosomiasis. PLoS Neglected Tropical Diseases 5, e1151.

Jittapalapong, S., Inpankaew, T., Sarataphan, N., Herbreteau, V., Hugot, J. P., Morand, S. and Stich, R. W. (2008). Molecular detection of divergent trypanosomes among rodents of Thailand. Infection, Genetics and Evolution 8, 445-449.

Jodrell, D. I., Reyno, L. M., Sridhara, R., Eisenberger, M. A., Tkaczuk, K. H., Zuhowski, E. G., Sinibaldi, V. J., Novak, M. J. and Egorin, M. J. (1994). Suramin: development of a population pharmacokinetic model and its use with intermittent short infusions to control plasma drug concentration in patients with prostate cancer. Fournal of Clinical Oncology 12, 166-175.

Jones, T. W. and Davila, A. M. (2001). Trypanosoma vivax-out of Africa. Trends in Parasitology 17, 99-101.

Jones, D., Nyalwidhe, J., Tetley, L. and Barrett, M.P. (2007) McArthur revisited: fluorescence microscopes for field diagnostics. Trends in Parasitology 23, 468-469.

Joshi, P.P., Shegokar, V.R., Powar, R.M., Herder, S., Katti, R., Salkar, H. R., Dani, V. S., Bhargava, A., Jannin, J. and Truc, P. (2005) Human trypanosomiasis caused by Trypanosoma evansi in India: the first case report. American Fournal of Tropical Medicine and Hygiene 73, 491-495. Joshua, R. A. and Kayit, Y.S. (1984). The course of fatal Trypanosoma simiae infection in domestic sheep. Acta Tropica 41, 91-92.

Joshua, R.A., Obwolo, M.J., Bwangamoi, O. and Mandebvu, E. (1995). Resistance to diminazine aceturate by Trypanosoma congolense from cattle in the Zambezi Valley of Zimbabwe. Veterinary Parasitology 60, 1-6. Kaminsky, R. and Brun, R. (1993). In vitro assays to determine drug sensitivities of African trypanosomes: a review. Acta Tropica 54, 279-289.

Kaminsky, R., Gumm, I. D., Zweygarth, E. and Chuma, F. (1990). A drug incubation infectivity test (DIIT) for assessing resistance in trypanosomes. Veterinary Parasitology 34, 335-343.

Kazibwe, A. J., Nerima, B., de Koning, H. P., Maser, P., Barrett, M. P. and Matovu, E. (2009). Genotypic status of the TbAT1/P2 adenosine transporter of Trypanosoma brucei gambiense isolates from Northwestern Uganda following melarsoprol withdrawal. PLoS Neglected Tropical Diseases 3, e523.

Kellner, H. M., Eckert, H. G. and Volz, M. H. (1985). Studies in cattle on the disposition of the anti-trypanosomal drug diminazene diaceturate (Berenil). Tropical Medicine and Parasitology 36, 199-204.

Kihurani, D. O., Nantulya, V. M., Mbiuki, S. M., Mogoa, E., NguhiuMwangi, J. and Mbithi, P. M. (1994). Trypanosoma brucei, T. congolense and T. vivax infections in horses on a farm in Kenya. Tropical Animal Health and Production 26, 95-101.

Kinabo, L. D. (1993). Pharmacology of existing drugs for animal trypanosomiasis. Acta Tropica 54, 169-183.

Kinabo, L. D. and Bogan, J. A. (1988). The pharmacology of isometamidium. Fournal of Veterinary Pharmacology and Therapeutics 11, 233-245.

Knobloch, J., Tischendorf, F., Konig, J. and Mehlitz, D. (1984). Evaluation of immunoassays for diagnosis and management of sleeping sickness in Liberia. Tropenmedizin und Parasitologie 35, 137-140.

Knoppe, T. N., Bauer, B., McDermott, J. J., Peregrine, A.S., Mehlitz, D. and Clausen, P.H. (2006). Isometamidium sensitivity of Trypanosoma congolense stocks from cattle in West Africa tested in mice and the drug incubation infectivity test. Acta Tropica 97, 108-116.

Kocher, A., Desquesnes, M., Yangtara, S., Morand, S. and Jittapalapong, S. (2015). Is the oriental house rat (Rattus tanezumi) a potential reservoir for Trypanosoma evansi in Thailand? Fournal of Wildlife Diseases 51, 719-723.

Kroubi, M., Karembe, H. and Betbeder, D. (2011). Drug delivery systems in the treatment of African trypanosomiasis infections. Expert Opinion on Drug Delivery 8, 735-747.

Kupper, W. and Wolters, M. (1983). Observation on drug resistance of Trypanosoma (Nannomonas) congolense and Trypanosoma (Duttonella) vivax in cattle at a feedlot in the Northern Ivory Coast. Tropenmedizin und Parasitologie 34, 203-205.

Kuriakose, S., Muleme, H. M., Onyilagha, C., Singh, R., Jia, P. and Uzonna, J. E. (2012). Diminazene aceturate (Berenil) modulates the host cellular and inflammatory responses to Trypanosoma congolense infection. PLoS ONE 7, e48696.

La Greca, F. and Magez, S. (2011). Vaccination against trypanosomiasis: can it be done or is the trypanosome truly the ultimate immune destroyer and escape artist? Human Vaccines 7, 1225-1233.

Lai, D. H., Hashimi, H., Lun, Z. R., Ayala, F. J. and Lukes, J. (2008) Adaptations of Trypanosoma brucei to gradual loss of kinetoplast DNA: Trypanosoma equiperdum and Trypanosoma evansi are petite mutants of T. brucei. Proceedings of the National Academy of Sciences of the United States of America 105, 1999-2004.

Lanteri, C. A., Tidwell, R. R. and Meshnick, S. R. (2008). The mitochondrion is a site of trypanocidal action of the aromatic diamidine DB75 in bloodstream forms of Trypanosoma brucei. Antimicrobial Agents and Chemotherapy 52, 875-882.

Leach, T. M. and Roberts, C. J. (1981). Present status of chemotherapy and chemoprophylaxis of animal trypanosomiasis in the Eastern hemisphere. Pharmacology \& Therapeutics 13, 91-147.

Liao, D. and Shen, J. (2010). Studies of quinapyramine-resistance of Trypanosoma brucei evansi in China. Acta Tropica 116, 173-177.

Lindner, A. K. and Priotto, G. (2010). The unknown risk of vertical transmission in sleeping sickness-a literature review. PLoS Neglected Tropical Diseases 4, e783.

Livingstone, D. (1858). Arsenic as a remedy for the tsetse bite. British Medical Fournal 1, 360-361.

Luckins, A. G. (1988). Trypanosoma evansi in Asia. Parasitology Today 4, 137-142.

Lun, Z. R., Fang, Y., Wang, C. J. and Brun, R. (1993). Trypanosomiasis of domestic animals in China. Parasitology Today 9, 41-45.

Lun, Z. R., Lai, D. H., Li, F. J., Lukes, J. and Ayala, F. J. (2010) Trypanosoma brucei: two steps to spread out from Africa. Trends in Parasitology 26, 424-427.

Magona, J. W., Walubengo, J. and Odimin, J. T. (2008). Acute haemorrhagic syndrome of bovine trypanosomosis in Uganda. Acta Tropica 107 186-191.

Maia da Silva, F., Marcili, A., Ortiz, P. A., Epiphanio, S., Campaner, M., Catao-Dias, J.L., Shaw, J. J., Camargo, E.P. and Teixeira, M. M. (2010). Phylogenetic, morphological and behavioura analyses support host switching of Trypanosoma (Herpetosoma) lewisi from domestic rats to primates. Infection, Genetics and Evolution 10, 522-529.

Mamman, M., Aliu, Y. O. and Peregrine, A. S. (1993). Comparative pharmacokinetics of diminazene in noninfected Boran (Bos indicus) cattle and Boran cattle infected with Trypanosoma congolense. Antimicrobial Agents and Chemotherapy 37, 1050-1055.

Mamoudou, A., Delespaux, V., Chepnda, V., Hachimou, Z., Andrikaye, J. P., Zoli, A. and Geerts, S. (2008). Assessment of the occurrence of trypanocidal drug resistance in trypanosomes of naturally infected cattle in the Adamaoua region of Cameroon using the standard mouse test and molecular tools. Acta Tropica 106, 115-118.

Masumu, J., Marcotty, T., Geysen, D., Geerts, S., Vercruysse, J., Dorny, P. and Van den Bossche, P. (2006). Comparison of the virulence of Trypanosoma congolense strains isolated from cattle in a trypanosomiasis endemic area of eastern Zambia. International Fournal for Parasitology 36 497-501.

Mathis, A. M., Holman, J. L., Sturk, L. M., Ismail, M. A., Boykin, D. W. Tidwell, R. R. and Hall, J. E. (2006). Accumulation and intracellular distribution of antitrypanosomal diamidine compounds DB75 and DB820 in African trypanosomes. Antimicrobial Agents and Chemotherapy 50, 2185-2191. Matovu, E., Stewart, M. L., Geiser, F., Brun, R., Maser, P., Wallace, L. J., Burchmore, R. J., Enyaru, J. C., Barrett, M.P., Kaminsky, R., Seebeck, T. and de Koning, H.P. (2003). Mechanisms of arsenical and diamidine uptake and resistance in Trypanosoma brucei. Eukaryotic Cell 2, 1003-1008.

Mbwambo, H. A., Mella, P. N. and Lekaki, K. A. (1988). Berenil (diminazene aceturate)-resistant Trypanosoma congolense in cattle under natural tsetse challenge at Kibaha, Tanzania. Acta Tropica 45, 239-244.

McCall, J. W., McTier, T. L., Dzimianski, M. T., Raynaud, J. P. and Holmes, R. A. (1994). Clinical prophylactic activity of melarsomine dihydrochloride (RM 340) against Dirofilaria immitis in heartworm-naive beagles exposed to natural infection in three southeastern states. Veterinary Parasitology 55, 205-219.

Mdachi, R. E., Murilla, G. A., Omukuba, J. N. and Cagnolati, V. (1995). Disposition of diminazene aceturate (Berenil) in trypanosomeinfected pregnant and lactating cows. Veterinary Parasitology 58, 215-225. 
Mehlitz, D., Zillmann, U., Scott, C. M. and Godfrey, D. G. (1982). Epidemiological studies on the animal reservoir of Gambiense sleeping sickness. Part III. Characterization of trypanozoon stocks by isoenzymes and sensitivity to human serum. Tropenmedizin und Parasitologie 33, 113-118

Melendez, R. D., Forlano, M. and Figueroa, W. (1993). Perinatal infection with Trypanosoma vivax in a calf in Venezuela. Fournal of Parasitology 79, 293-294.

Moloo, S. K., Kabata, J. M. and Gitire, N. M. (2000). Study on the mechanical transmission by tsetse fly Glossina morsitans centralis of Trypanosoma vivax, T. congolense or T. brucei brucei to goats. Acta Tropica 74, 105-108.

Moti, Y., Fikru, R., Van Den Abbeele, J., Buscher, P., Van den Bossche, P., Duchateau, L. and Delespaux, V. (2012). Ghibe river basin in Ethiopia: present situation of trypanocidal drug resistance in Trypanosoma congolense using tests in mice and PCR-RFLP. Veterinary Parasitology 189, 197-203.

Moti, Y., De Deken, R., Thys, E., Van Den Abbeele, J., Duchateau, L. and Delespaux, V. (2015). PCR and microsatellite analysis of diminazene aceturate resistance of bovine trypanosomes correlated to knowledge, attitude and practice of livestock keepers in South-Western Ethiopia. Acta Tropica 146, 45-52.

Moulton, J. E. (1986). Relapse infection after chemotherapy in goats experimentally infected with Trypanosoma brucei: pathological changes in central nervous system. Veterinary Pathology 23, 21-28.

Mulla, A. F. and Rickman, L. R. (1988). How do African game animals control trypanosome infections? Parasitology Today 4, 352-354

Munday, J. C., Rojas Lopez, K. E., Eze, A. A., Delespaux, V., Van Den Abbeele, J., Rowan, T., Barrett, M.P., Morrison, L. J. and de Koning, H.P. (2013). Functional expression of TcoAT1 reveals it to be a P1-type nucleoside transporter with no capacity for diminazene uptake. International Fournal for Parasitology: Drugs and Drug Resistance 3, 69-76.

Munday, J. C., Eze, A.A., Baker, N., Glover, L., Clucas, C., Aguinaga, A. D., Natto, M. J., Teka, I. A., McDonald, J., Lee, R. S., Graf, F. E., Ludin, P., Burchmore, R. J., Turner, C. M., Tait, A., MacLeod, A., Maser, P., Barrett, M.P., Horn, D. and de Koning, H. P. (2014). Trypanosoma brucei aquaglyceroporin 2 is a highaffinity transporter for pentamidine and melaminophenyl arsenic drugs and the main genetic determinant of resistance to these drugs. Fournal of Antimicrobial Chemotherapy 69, 651-663.

Munday, J. C., Settimo, L. and de Koning, H. P. (2015a). Transport proteins determine drug sensitivity and resistance in a protozoan parasite, Trypanosoma brucei. Frontiers in Pharmacology 6, 32.

Munday, J. C., Tagoe, D. N., Eze, A. A., Krezdorn, J. A., Rojas Lopez, K. E., Alkhaldi, A. A., McDonald, F., Still, J., Alzahrani, K. J., Settimo, L. and de Koning, H.P. (2015b). Functional analysis of drug resistance-associated mutations in the Trypanosoma brucei adenosine transporter 1 (TbAT1) and the proposal of a structural model for the protein. Molecular Microbiology 96, 887-900.

Mungube, E. O., Vitouley, H.S., Allegye-Cudjoe, E., Diall, O., Boucoum, Z., Diarra, B., Sanogo, Y., Randolph, T., Bauer, B., Zessin, K. H. and Clausen, P. H. (2012). Detection of multiple drug-resistant Trypanosoma congolense populations in village cattle of south-east Mali. Parasites $\Xi^{\circ}$ Vectors 5, 155.

Munstermann, S., Mbura, R. J., Maloo, S. H. and Lohr, K. F. (1992). Trypanosomiasis control in Boran cattle in Kenya: a comparison between chemoprophylaxis and a parasite detection and intravenous treatment method using isometamidium chloride. Tropical Animal Health and Production 24, 17-27.

Murilla, G. A., Mdachi, R. E., Ismail, A. A. and Karanja, W. M. (1996). Bioavailability, pharmacokinetics, and tissue distribution of ${ }^{14} \mathrm{C}$ homidium after parenteral administration to Boran cattle. Fournal of Veterinary Pharmacology and Therapeutics 19, 142-148.

Murilla, G. A., Holmes, P.H., Peregrine, A.S., Eisler, M. C. and Ndung'u, J. M. (1999). Some pharmacokinetic parameters of the trypanocidal drug homidium bromide in Friesian and Boran steers using an enzyme-linked immunosorbent assay (ELISA). Fournal of Veterinary Pharmacology and Therapeutics 22, 295-300.

Murray, M., Morrison, W. I. and Whitelaw, D. D. (1982). Host susceptibility to African trypanosomiasis: trypanotolerance. Advances in Parasitology 21, 1-68.

Mutugi, M. W., Boid, R. and Luckins, A. G. (1994). Experimental induction of suramin-resistance in cloned and uncloned stocks of Trypanosoma evansi using immunosuppressed and immunocompetent mice. Tropical Medicine and Parasitology 45, 232-236.

Myburgh, E., Coles, J. A., Ritchie, R., Kennedy, P. G., McLatchie, A. P., Rodgers, J., Taylor, M. C., Barrett, M.P., Brewer, J.M. and Mottram, J. C. (2013). In vivo imaging of trypanosome-brain interactions and development of a rapid screening test for drugs against CNS stage trypanosomiasis. PLoS Neglected Tropical Diseases 7, e2384.

Naessens, J. (2006). Bovine trypanotolerance: a natural ability to prevent severe anaemia and haemophagocytic syndrome? International fournal for Parasitology 36, 521-528.

Nare, B., Wring, S., Bacchi, C., Beaudet, B., Bowling, T., Brun, R., Chen, D., Ding, C., Freund, Y., Gaukel, E., Hussain, A., Jarnagin, K., Jenks, M., Kaiser, M., Mercer, L., Mejia, E., Noe, A., Orr, M., Parham, R., Plattner, J., Randolph, R., Rattendi, D., Rewerts, C., Sligar, J., Yarlett, N., Don, R. and Jacobs, R. (2010). Discovery of novel orally bioavailable oxaborole 6-carboxamides that demonstrate cure in a murine model of late-stage central nervous system African trypanosomiasis. Antimicrobial Agents and Chemotherapy 54, 4379-4388.

Ndoutamia, G., Moloo, S. K., Murphy, N. B. and Peregrine, A.S. (1993). Derivation and characterization of a quinapyramine-resistant clone of Trypanosoma congolense. Antimicrobial Agents and Chemotherapy 37, 1163-1166.

Newton, B. A. (1962). Inactivation of ribosomes by antrycide. Biochemical Fournal 84, 109 .

Newton, B. A. (1966). Effects of antrycide on nucleic acid synthesis and function. Symposium of the Society for General Microbiology 16, 213-234.

Osman, A. S., Jennings, F. W. and Holmes, P. H. (1992). The rapid development of drug-resistance by Trypanosoma evansi in immunosuppressed mice. Acta Tropica 50, 249-257.

Osorio, A.L., Madruga, C. R., Desquesnes, M., Soares, C. O., Ribeiro, L. R. and Costa, S.C. (2008). Trypanosoma (Duttonella) vivax: its biology, epidemiology, pathogenesis, and introduction in the New World-a review. Memórias do Instituto Oswaldo Cruz 103, 1-13.

Paine, M.F., Wang, M.Z., Generaux, C. N., Boykin, D.W., Wilson, W. D., de Koning, H. P., Olson, C. A., Pohlig, G., Burri, C., Brun, R., Murilla, G. A., Thuita, J.K., Barrett, M.P. and Tidwell, R. R. (2010). Diamidines for human African trypanosomiasis. Current Opinion in Investigational Drugs 11, 876-883.

Pal, A., Hall, B. S. and Field, M. C. (2002). Evidence for a non-LDLmediated entry route for the trypanocidal drug suramin in Trypanosoma brucei. Molecular and Biochemical Parasitology 122, 217-221.

Pascucci, I., Di Provvido, A., Camma, C., Di Francesco, G., Calistri, P., Tittarelli, M., Ferri, N., Scacchia, M. and Caporale, V. (2013). Diagnosis of dourine in outbreaks in Italy. Veterinary Parasitology 193, 30-38.

Payne, R. C., Sukanto, I. P., Djauhari, D., Partoutomo, S., Wilson, A. J., Jones, T. W., Boid, R. and Luckins, A. G. (1991). Trypanosoma evansi infection in cattle, buffaloes and horses in Indonesia. Veterinary Parasitology 38, 109-119.

Payne, R. C., Sukanto, I. P., Partoutomo, S. and Jones, T. W. (1994). Efficacy of Cymelarsan treatment of suramin resistant Trypanosoma evansi in cattle. Tropical Animal Health and Production 26, 92-94.

Pepin, J. and Khonde, N. (1996). Relapses following treatment of earlystage Trypanosoma brucei gambiense sleeping sickness with a combination of pentamidine and suramin. Transactions of the Royal Society of Tropical Medicine and Hygiene 90, 183-186.

Peregrine, A.S. (1994). Chemotherapy and delivery systems: haemoparasites. Veterinary Parasitology 54, 223-248.

Peregrine, A. S. and Mamman, M. (1993). Pharmacology of diminazene: a review. Acta Tropica 54, 185-203.

Peregrine, A. S., Gray, M. A. and Moloo, S. K. (1997). Cross-resistance associated with development of resistance to isometamidium in a clone of Trypanosoma congolense. Antimicrobial Agents and Chemotherapy 41, 1604-1606.

Pinder, M. and Authie, E. (1984). The appearance of isometamidium resistant Trypanosoma congolense in West Africa. Acta Tropica 41, 247-252. Portugal, J. (1994). Berenil acts as a poison of eukaryotic topoisomerase II. FEBS Letters 344, 136-138.

Pospichal, H., Brun, R., Kaminsky, R. and Jenni, L. (1994). Induction of resistance to melarsenoxide cysteamine (Mel Cy) in Trypanosoma brucei brucei. Acta Tropica 58, 187-197.

Priotto, G., Kasparian, S., Mutombo, W., Ngouama, D., Ghorashian, S., Arnold, U., Ghabri, S., Baudin, E., Buard, V., Kazadi-Kyanza, S., Ilunga, M., Mutangala, W., Pohlig, G., Schmid, C., Karunakara, U., Torreele, E. and Kande, V. (2009). Nifurtimox-eflornithine combination therapy for second-stage African Trypanosoma brucei gambiense trypanosomiasis: a multicentre, randomised, phase III, non-inferiority trial. Lancet 374, 56-64.

Pumhom, P., Morand, S., Tran, A., Jittapalapong, S. and Desquesnes, M. (2015). Trypanosoma from rodents as potential source of infection in human-shaped landscapes of South-East Asia. Veterinary Parasitology 208, 174-180. 
Ranjithkumar, M., Saravanan, B.C., Yadav, S. C., Kumar, R., Singh, R. and Dey, S. (2014). Neurological trypanosomiasis in quinapyramine sulfate-treated horses-a breach of the blood-brain barrier? Tropical Animal Health and Production 46, 371-377.

Räz, B., Iten, M., Grether-Buhler, Y., Kaminsky, R. and Brun, R. (1997). The Alamar Blue ${ }^{\circledR}$ assay to determine drug sensitivity of African trypanosomes (T. b. rhodesiense and T.b. gambiense) in vitro. Acta Tropica 68, 139-147.

Reid, S. A. (2002). Trypanosoma evansi control and containment in Australasia. Trends in Parasitology 18, 219-224.

Riou, G. F., Belnat, P. and Benard, J. (1980). Complete loss of kinetoplast DNA sequences induced by ethidium bromide or by acriflavine in Trypanosoma equiperdum. Fournal of Biological Chemistry 255, 5141-5144. Rowlands, G. J., Leak, S. G., Peregrine, A. S., Nagda, S. M. Mulatu, W. and d'Ieteren, G. D. (2001). The incidence of new and the prevalence and persistence of recurrent trypanosome infections in cattle in southwest Ethiopia exposed to a high challenge with drug-resistant parasites. Acta Tropica 79, 149-163.

Roy Chowdhury, A., Bakshi, R., Wang, J., Yildirir, G., Liu, B. Pappas-Brown, V., Tolun, G., Griffith, J. D., Shapiro, T. A., Jensen, R. E. and Englund, P. T. (2010). The killing of African trypanosomes by ethidium bromide. PLoS Pathogens 6, e1001226.

Sahin, A., Asencio, C., Izotte, J., Pillay, D., Coustou, V., Karembe, H. and Baltz, T. (2014). The susceptibility of Trypanosoma congolense and Trypanosoma brucei to isometamidium chloride and its synthetic impurities. Veterinary Parasitology 203, 270-275.

Salim, B., Bakheit, M. A. and Sugimoto, C. (2014). Molecular detection of equine trypanosomes in the Sudan. Veterinary Parasitology 200, 246-250. Sanderson, L., Dogruel, M., Rodgers, J., De Koning, H.P. and Thomas, S. A. (2009). Pentamidine movement across the murine bloodbrain and blood-cerebrospinal fluid barriers: effect of trypanosome infection, combination therapy, P-glycoprotein, and multidrug resistance-associated protein. Fournal of Pharmacology and Experimental Therapeutics 329, 967-977. Sarataphan, N., Vongpakorn, M., Nuansrichay, B., Autarkool, N., Keowkarnkah, T., Rodtian, P., Stich, R. W. and Jittapalapong, S. (2007). Diagnosis of a Trypanosoma lewisi-like (Herpetosoma) infection in a sick infant from Thailand. Fournal of Medical Microbiology 56, 11181121

Schnaufer, A., Domingo, G. J. and Stuart, K. (2002). Natural and induced dyskinetoplastic trypanosomatids: how to live without mitochondrial DNA. International Fournal for Parasitology 32, 1071-1084.

Schumann, B. G., Jutzi, P. and Roditi, I. (2011). Genome-wide RNAi screens in bloodstream form trypanosomes identify drug transporters. Molecular and Biochemical Parasitology 175, 91-94.

Scott, A. G., Tait, A. and Turner, C. M. (1996). Characterisation of cloned lines of Trypanosoma brucei expressing stable resistance to MelCy and suramin. Acta Tropica 60, 251-262.

Seidl, A., Moraes, A. S., Aguilar, R. and Silva, M. S. (1998). A financial analysis of treatment strategies for Trypanosoma evansi in the Brazilian Pantanal. Preventive Veterinary Medicine 33, 219-234.

Seidl, A., Davila, A. M. and Silva, R. A. (1999). Estimated financial impact of Trypanosoma vivax on the Brazilian pantanal and Bolivian lowlands. Memórias do Instituto Oswaldo Cruz 94, 269-272.

Shameer, S., Logan-Klumpler, F. J., Vinson, F., Cottret, L. Merlet, B., Achcar, F., Boshart, M., Berriman, M., Breitling, R., Bringaud, F., Butikofer, P., Cattanach, A.M., BannermanChukualim, B., Creek, D. J., Crouch, K., de Koning, H. P., Denise, H., Ebikeme, C., Fairlamb, A.H., Ferguson, M. A., Ginger, M. L., Hertz-Fowler, C., Kerkhoven, E. J., Maser, P., Michels, P.A., Nayak, A., Nes, D. W., Nolan, D.P., Olsen, C., Silva-Franco, F. et al. (2015). TrypanoCyc: a community-led biochemical pathways database for Trypanosoma brucei. Nucleic Acids Research 43, D637-D644.

Shapiro, T. A. and Englund, P. T. (1990). Selective cleavage of kinetoplast DNA minicircles promoted by antitrypanosomal drugs. Proceedings of the National Academy of Sciences of the United States of America 87, 950-954.

Shaw, A. P., Cecchi, G., Wint, G. R., Mattioli, R. C. and Robinson, T. P. (2014). Mapping the economic benefits to livestock keepers from intervening against bovine trypanosomosis in Eastern Africa. Preventive Veterinary Medicine 113, 197-210.

Shaw, A.P., Wint, G. R., Cecchi, G., Torr, S. J., Mattioli, R. C. and Robinson, T.P. (2015). Mapping the benefit-cost ratios of interventions against bovine trypanosomosis in Eastern Africa. Preventive Veterinary Medicine 122, 406-416.

Simarro, P.P., Franco, J., Diarra, A., Postigo, J. A. and Jannin, J. (2012). Update on field use of the available drugs for the chemotherapy of human African trypanosomiasis. Parasitology 139, 842-846.
Simo, G. and Rayaisse, J. B. (2015). Challenges facing the elimination of sleeping sickness in west and central Africa: sustainable control of animal trypanosomiasis as an indispensable approach to achieve the goal. Parasites $\Xi^{\circ}$ Vectors 8, 640

Singla, L. D., Juyal, P. D. and Sharma, N. S. (2010). Immune responses to haemorrhagic septicaemia (HS) vaccination in Trypanosoma evansi infected buffalo-calves. Tropical Animal Health and Production 42, 589-595. Sinyangwe, L., Delespaux, V., Brandt, J., Geerts, S., Mubanga, J., Machila, N., Holmes, P.H. and Eisler, M. C. (2004). Trypanocidal drug resistance in eastern province of Zambia. Veterinary Parasitology 119, 125-135.

Song, J., Baker, N., Rothert, M., Henke, B., Jeacock, L., Horn, D. and Beitz, E. (2016). Pentamidine is not a permeant but a nanomolar inhibitor of the Trypanosoma brucei aquaglyceroporin-2. PLoS Pathogens 12 e1005436.

Spinks, A. (1950). Absorption and persistence of antrycide. British fournal of Pharmacology and Chemotherapy 5, 445-454.

Steinmann, P., Stone, C. M., Sutherland, C.S., Tanner, M. and Tediosi, F. (2015). Contemporary and emerging strategies for eliminating human African trypanosomiasis due to Trypanosoma brucei gambiense: review. Tropical Medicine \& International Health 20, 707-718.

Stephen, L. E. (1966). Pig Trypanosomiasis in Tropical Africa. In Review Series of the Commonwealth Bureau of Animal Health, Vol. 8. Commonwealth Agricultural Bureaux, Farnham House, Farnham Royal, Bucks, UK

Stevenson, P., Sones, K. R., Gicheru, M. M. and Mwangi, E. K. (1995). Comparison of isometamidium chloride and homidium bromide as prophylactic drugs for trypanosomiasis in cattle at Nguruman, Kenya. Acta Tropica 59, 77-84.

Steverding, D. (2008). The history of African trypanosomiasis. Parasites छ Vectors 1,3

Steverding, D. (2010). The development of drugs for treatment of sleeping sickness: a historical review. Parasites \& Vectors 3, 15.

Stewart, M. L., Krishna, S., Burchmore, R. J., Brun, R., de Koning, H. P., Boykin, D. W., Tidwell, R. R., Hall, J. E. and Barrett, M.P. (2005). Detection of arsenical drug resistance in Trypanosoma bruce $i$ with a simple fluorescence test. Lancet 366, 486-487. Stewart, M. L., Burchmore, R. J., Clucas, C., Hertz-Fowler, C., Brooks, K., Tait, A., MacLeod, A., Turner, C. M., de Koning, H.P., Wong, P.E. and Barrett, M.P. (2010). Multiple genetic mechanisms lead to loss of functional TbAT1 expression in drug-resistant trypanosomes. Eukaryotic Cell 9, 336-343.

Suswam, E. A., Ross, C. A. and Martin, R. J. (2003). Changes in adenosine transport associated with melaminophenyl arsenical (Mel CY) resistance in Trypanosoma evansi: down-regulation and affinity changes of the P2 transporter. Parasitology 127, 543-549.

Suswam, E. A., Taylor, D. W., Ross, C. A. and Martin, R. J. (2001). Changes in properties of adenosine transporters in Trypanosoma evans and modes of selection of resistance to the melaminophenyl arsenical drug, Mel Cy. Veterinary Parasitology 102, 193-208.

Sutcliffe, O. B., Skellern, G. G., Araya, F., Cannavan, A., Sasanya, J. J., Dungu, B., van Gool, F., Munstermann, S. and Mattioli, R. C. (2014). Animal trypanosomosis: making quality control of trypanocidal drugs possible. Revue Scientifique et Technique (International Office of Epizootics) 33, 813-830.

Sutherland, I. A. and Holmes, P. H. (1993). Alterations in drug transport in resistant Trypanosoma congolense. Acta Tropica 54, 271-278.

Sutherland, I. A., Mounsey, A. and Holmes, P. H. (1992). Transport of isometamidium (Samorin) by drug-resistant and drug-sensitive Trypanosoma congolense. Parasitology 104 (Pt 3), 461-467.

Swallow, B. M. (2000). Impacts of Trypanosomiasis on African Agriculture. PAAT Technical and Scientific Series No. 2. Food and Agriculture Organisation of the United Nations (FAO), Rome, Italy

Takeet, M. I., Fagbemi, B. O., De Donato, M., Yakubu, A., Rodulfo, H. E., Peters, S. O., Wheto, M. and Imumorin, I. G. (2013). Molecular survey of pathogenic trypanosomes in naturally infected Nigerian cattle. Research in Veterinary Science 94, 555-561.

Tamarit, A., Gutierrez, C., Arroyo, R., Jimenez, V., Zagala, G., Bosch, I., Sirvent, J., Alberola, J., Alonso, I. and Caballero, C. (2010). Trypanosoma evansi infection in mainland Spain. Veterinary Parasitology 167, 74-76.

Tamarit, A., Tejedor-Junco, M. T., Gonzalez, M., Alberola, J. and Gutierrez, C. (2011). Morphological and biometrical features of Trypanosoma evansi isolates from an outbreak in mainland Spain. Veterinary Parasitology 177, 152-156.

Taylor, K. and Authié, E. M.-L. (2004). Pathogenesis of animal trypanosomiasis. In The Trypanosomiases (ed. Maudlin, I., Holmes, P. H. and Miles, M. A.), pp. 331-353. CAB International, Wallingford, UK 
Tchamdja, E., Kulo, A. E., Akoda, K., Teko-Agbo, A., Assoumy, A. M., Niang, E. M., Batawui, K., Adomefa, K., Bankole, A. A., Kombiagou, K., Hoppenheit, A., Clausen, P.H., Mattioli, R.C., Peter, R., Napier, G. B., De Deken, R., Marcotty, T., Van Den Abbeele, J. and Delespaux, V. (2016). Drug quality analysis through high performance liquid chromatography of isometamidium chloride hydrochloride and diminazene diaceturate purchased from official and unofficial sources in Northern Togo. Preventive Veterinary Medicine 126, $151-158$

Teka, I. A., Kazibwe, A. J., El-Sabbagh, N., Al-Salabi, M. I., Ward, C. P., Eze, A. A., Munday, J. C., Maser, P., Matovu, E., Barrett, M. P. and de Koning, H.P. (2011). The diamidine diminazene aceturate is a substrate for the high-affinity pentamidine transporter: implications for the development of high resistance levels in trypanosomes. Molecular Pharmacology 80, 110-116.

Toro, M., Leon, E., Lopez, R., Pallota, F., Garcia, J. A. and Ruiz, A. (1983). Effect of isometamidium on infections by Trypanosoma vivax and T. evansi in experimentally-infected animals. Veterinary Parasitology 13, $35-43$

Tran, T., Napier, G., Rowan, T., Cordel, C., Labuschagne, M., Delespaux, V., Van Reet, N., Erasmus, H., Joubert, A. and Buscher, P. (2014). Development and evaluation of an ITS1 "Touchdown" PCR for assessment of drug efficacy against animal African trypanosomosis. Veterinary Parasitology 202, 164-170.

Truc, P., Buscher, P., Cuny, G., Gonzatti, M. I., Jannin, J., Joshi, P., Juyal, P., Lun, Z. R., Mattioli, R., Pays, E., Simarro, P.P., Teixeira, M.M., Touratier, L., Vincendeau, P. and Desquesnes, M. (2013). Atypical human infections by animal trypanosomes. PLoS Neglected Tropical Diseases 7, e2256.

Tuntasuvan, D., Sarataphan, N. and Nishikawa, H. (1997). Cerebral trypanosomiasis in native cattle. Veterinary Parasitology 73, 357-363.

Tuntasuvan, D., Jarabrum, W., Viseshakul, N., Mohkaew, K., Borisutsuwan, S., Theeraphan, A. and Kongkanjana, N. (2003) Chemotherapy of surra in horses and mules with diminazene aceturate. Veterinary Parasitology 110, 227-233.

Uilenberg, G. (1998). A Field Guide for the Diagnosis, Treatment, and Prevention of African Animal Trypanosomosis. Food and Agriculture Organisation of the United Nations (FAO), Rome, Italy.

Unciti-Broceta, J. D., Arias, J. L., Maceira, J., Soriano, M., OrtizGonzalez, M., Hernandez-Quero, J., Munoz-Torres, M., de Koning, H. P., Magez, S. and Garcia-Salcedo, J. A. (2015). Specific cell targeting therapy bypasses drug resistance mechanisms in African trypanosomiasis. PLoS Pathogens 11, e1004942.

Van den Bossche, P. and Delespaux, V. (2011). Options for the control of tsetse-transmitted livestock trypanosomosis. An epidemiological perspective. Veterinary Parasitology 181, 37-2.

Van den Bossche, P., Doran, M. and Connor, R. J. (2000). An analysis of trypanocidal drug use in the Eastern Province of Zambia. Acta Tropica 75, 247-258.

Vanhollebeke, B., Truc, P., Poelvoorde, P., Pays, A., Joshi, P.P., Katti, R., Jannin, J. G. and Pays, E. (2006). Human Trypanosoma evansi infection linked to a lack of apolipoprotein L-I. New England Fournal of Medicine 355, 2752-2756.

Vansterkenburg, E. L., Coppens, I., Wilting, J., Bos, O. J., Fischer, M. J., Janssen, L. H. and Opperdoes, F. R. (1993). The uptake of the trypanocidal drug suramin in combination with low-density lipoproteins by Trypanosoma brucei and its possible mode of action. Acta Tropica 54, $237-250$.

Van Vinh, C. N., Buu, C. L., Desquesnes, M., Herder, S., Phu Huong, L. N., Campbell, J. I., Van Cuong, N., Yimming, B., Chalermwong, P., Jittapalapong, S., Ramon Franco, J., Tri Tue, N., Rabaa, M. A., Carrique-Mas, J., Pham Thi Thanh, T., Tran Vu Thieu, N., Berto, A., Thi Hoa, N., Van Minh Hoang, N., Canh Tu, N., Khac Chuyen, N., Wills, B., Tinh Hien, T., Thwaites, G. E., Yacoub, S. and Baker, S. (2016). A clinical and epidemiological investigation of the first reported human infection with the zoonotic parasite Trypanosoma evansi in Southeast Asia. Clinical Research in Infectious Diseases 62, 1002-1008.
Vincent, I. M., Creek, D., Watson, D. G., Kamleh, M. A., Woods, D. J., Wong, P. E., Burchmore, R. J. and Barrett, M. P. (2010). A molecular mechanism for eflornithine resistance in African trypanosomes. PLoS Pathogens 6, e1001204

Vitouley, H.S., Sidibe, I., Bengaly, Z., Marcotty, T., Van Den Abbeele, J. and Delespaux, V. (2012). Is trypanocidal drug resistance a threat for livestock health and production in endemic areas? Food for thoughts from Sahelian goats infected by Trypanosoma vivax in Bobo Dioulasso (Burkina Faso). Veterinary Parasitology 190, 349-354.

Voogd, T.E., Vansterkenburg, E. L., Wilting, J. and Janssen, L. H. (1993). Recent research on the biological activity of suramin. Pharmacological Reviews 45, 177-203.

Wainwright, M. (2010). Dyes, trypanosomiasis and DNA: a historical and critical review. Biotechnic \& Histochemistry 85, 341-354.

Welburn, S. C., Beange, I., Ducrotoy, M. J. and Okello, A. L. (2015). The neglected zoonoses-the case for integrated control and advocacy. Clinical Microbiology and Infection 21, 433-443.

Wellde, B. T., Chumo, D. A., Adoyo, M., Kovatch, R. M., Mwongela, G. N. and Opiyo, E. A. (1983). Haemorrhagic syndrome in cattle associated with Trypanosoma vivax infection. Tropical Animal Health and Production 15, 95-102.

Wenzler, T., Yang, S., Braissant, O., Boykin, D. W., Brun, R. and Wang, M.Z. (2013). Pharmacokinetics, Trypanosoma brucei gambiense efficacy, and time of drug action of DB829, a preclinical candidate for treatment of second-stage human African trypanosomiasis. Antimicrobial Agents Chemotherapy 57, 5330-5343.

Wesongah, J. O., Jones, T. W., Kibugu, J. K. and Murilla, G. A. (2004) A comparative study of the pharmacokinetics of isometamidium chloride in sheep and goats. Small Ruminant Research 53, 9-14.

Whitelaw, D. D., Gardiner, P. R. and Murray, M. (1988) Extravascular foci of Trypanosoma vivax in goats: the central nervous system and aqueous humor of the eye as potential sources of relapse infections after chemotherapy. Parasitology 97 (Pt 1), 51-61.

Wilkes, J. M., Peregrine, A. S. and Zilberstein, D. (1995). The accumulation and compartmentalization of isometamidium chloride in Trypanosoma congolense, monitored by its intrinsic fluorescence. The Biochemical fournal 312 (Pt 1), 319-327.

Wilkes, J. M., Mulugeta, W., Wells, C. and Peregrine, A. S. (1997) Modulation of mitochondrial electrical potential: a candidate mechanism for drug resistance in African trypanosomes. Biochemical fournal 326 (Pt 3), 755-761.

Williamson, J. (1970). Review of chemotherapeutic and chemoprophylactic agents. In The African Trypanosomiases (ed. Mulligan, H. W.), pp. 125221. George Allen and Unwin Ltd., London.

Williamson, J. and Desowitz, R.S. (1956). Prophylactic activity of suramin complexes in animal trypanosomiasis. Nature 177, 1074-1075.

Wilson, W. D., Tanious, F. A., Mathis, A., Tevis, D., Hall, J. E. and Boykin, D. W. (2008). Antiparasitic compounds that target DNA. Biochimie 90, 999-1014.

Witola, W. H., Inoue, N., Ohashi, K. and Onuma, M. (2004). RNAinterference silencing of the adenosine transporter-1 gene in Trypanosoma evansi confers resistance to diminazene aceturate. Experimental Parasitology 107, 47-57.

Witola, W. H., Tsuda, A., Inoue, N., Ohashi, K. and Onuma, M. (2005). Acquired resistance to berenil in a cloned isolate of Trypanosoma evansi is associated with upregulation of a novel gene, TeDR40. Parasitology 131, 635-646.

Zhang, Z. Q., Giroud, C. and Baltz, T. (1991). In vivo and in vitro sensitivity of Trypanosoma evansi and T. equiperdum to diminazene, suramin, MelCy, quinapyramine and isometamidium. Acta Tropica 50, 101-110.

Zhou, J., Shen, J., Liao, D., Zhou, Y. and Lin, J. (2004). Resistance to drug by different isolates Trypanosoma evansi in China. Acta Tropica 90, 271-275. Zweygarth, E., Gray, M. A. and Kaminsky, R. (1991). Axenic in vitro cultivation of Trypanosoma vivax trypomastigote forms. Tropical Medicine and Parasitology 42, 45-48.

Zweygarth, E., Moloo, S. K., Kaminsky, R. and Gray, M. A. (1992). Axenic in vitro cultivation of Trypanosoma simiae bloodstream trypomastigotes. Acta Tropica 52, 79-81. 